\title{
Modeling the Impacts of the Large-Scale Atmospheric Environment on Inland Flooding during the Landfall of Hurricane Floyd (1999)
}

\author{
Qianhong Tang, ${ }^{1}$ Lian Xie, ${ }^{2}$ Gary M. Lackmann, ${ }^{2}$ and Bin Liu ${ }^{2}$ \\ ${ }^{1}$ Public Meteorological Service Center, China Meteorological Administration, 100081 Beijing, China \\ ${ }^{2}$ Department of Marine, Earth and Atmospheric Sciences, North Carolina State University, NCSU/MEAS, P.O. Box 8208, \\ Raleigh, NC 27695, USA
}

Correspondence should be addressed to Bin Liu; bin_liu@ncsu.edu

Received 1 March 2013; Accepted 13 May 2013

Academic Editor: John M. Morrison

Copyright (C) 2013 Qianhong Tang et al. This is an open access article distributed under the Creative Commons Attribution License, which permits unrestricted use, distribution, and reproduction in any medium, provided the original work is properly cited.

\begin{abstract}
The contribution of the large-scale atmospheric environment to precipitation and flooding during Hurricane Floyd was investigated in this study. Through the vortex removal technique in the Weather Research and Forecasting (WRF) model, the vortex associated with Hurricane Floyd (1999) was mostly removed in the model initial conditions and subsequent integration. Results show that the environment-induced precipitation can account for as much as $22 \%$ of total precipitation in the innermost model domain covering North Carolina coastal area and 7\% in the focused hydrological study area. The high-resolution precipitation data from the WRF model was then used for input in a hydrological model to simulate river runoff. Hydrological simulation results demonstrate that without the tropical systems and their interactions with the large-scale synoptic environment the synoptic environment would only contribute $10 \%$ to the total discharge at the Tarboro gauge station. This suggests that Hurricane Floyd and Hurricane Dennis preceding it, along with the interactions between these tropical systems and the large-scale environment, have contributed to the bulk (90\%) of the record amount of flood water in the Tar-Pamlico River Basin.
\end{abstract}

\section{Introduction}

Hurricane Floyd in September 1999 caused disastrous flooding along the US Atlantic Coast from South Carolina to Massachusetts. Flooding was particularly severe and prolonged in eastern portions of the state of North Carolina, where the combined effects of Hurricanes Dennis and Floyd resulted in greater flood-flow loadings of water and contaminants to Pamlico Sound, North Carolina, than any previously recorded events [1]. Over $50 \mathrm{~cm}$ of rain fell in isolated areas of North Carolina with widespread amounts exceeding $20 \mathrm{~cm}$ stretching from the Carolina Piedmont into southeastern New York [2]. Previous studies (e.g., [1, 3, 4]) indicated that this severe flooding was not only caused by the combination of Dennis and Floyd, but also due to the enhancement of precipitation after interaction with a mid-latitude trough during Floyd's landfall. The effect of the previous rainfall event, Hurricane Dennis, has been studied and quantified by Tang et al. [5]. However, the quantitative relations between the synoptic-scale environment, such as a trough/ridge system, and its associated precipitation during Floyd's landfall are still unclear.

The large-scale atmospheric environment hundreds to thousand kilometers away from a tropical cyclone (TC) may play an important role in TC landfall. The intensity of the troughs/ridges can affect the track, speed, intensity, and duration of TCs (e.g., [3, 6-9]). These features may further affect the rainfall amount and distribution. Many efforts have been devoted to understanding how environmental features affect TC and the resulting precipitation distribution (e.g., $[3,4,10,11])$. These studies can be grouped, according to focus, into three primary aspects.

The first one is the influence of extratropical transition (ET). A significant number of TCs move into the midlatitude and transform into extratropical cyclones (usually occurring in the $30-40^{\circ} \mathrm{N}$ latitude band). This process is generally referred to as ET. During ET, a cyclone frequently acquires increased forward motion and sometimes intensifies 
substantially so that such systems pose a serious threat to land and maritime activities. Atallah and Bosart [3] stated that the transport of tropical air masses into the midlatitudes resulted in a large increase in the available potential energy (APE) of the atmosphere. The approaching midlatitude trough provided a mechanism by which this APE was converted to kinetic energy through thermally direct circulations, resulting in a rather powerful extratropical cyclone. Hurricane David in 1979 regained power over land just prior to undergoing ET as it lifted the tropopause ahead of the mid-latitude trough due to diabatic heating from deep convection associated with the TC [12]. Atallah and Bosart [3] diagnosed the dynamics associated with the ET of Floyd and found that strong isentropic ascent can lead to copious amounts of precipitation. The juxtaposition of the relatively cool dry air of the mid-latitude trough and the warm moist air associated with Floyd produced an intense, troposphere-deep baroclinic zone. The circulation center of Floyd then interacted with this baroclinic zone, producing deep isentropic ascent and precipitation to the north of Floyd. The conceptual model advanced by Harr and Elsberry [13] and Harr et al. [14] indicates that strong ET tends to produce significant precipitation to the northeast of the TC. These features were favored when the main mid-latitude trough was located northwest of the TC.

The second aspect is hurricane-trough interaction, a topic of numerous investigations over the years (e.g., [6, 7, 15-19]). In a study of interactions between TCs and upper-tropospheric troughs, Hanley et al. [6] performed a composite of trough interactions with 121 Atlantic TCs in an attempt to differentiate between troughs that led to intensification and those that led to decay. Trough interactions were classified into four categories, that is, favorable superposition (TC intensifies with an upper-tropospheric PV maximum within $400 \mathrm{~km}$ of the TC center), unfavorable superposition, favorable distant interaction (upper PV maximum between 400 and $1000 \mathrm{~km}$ from the TC center), and unfavorable distant interaction. In the superposition case, there is an upper positive PV maximum within $400 \mathrm{~km}$ of the TC center. Within $400 \mathrm{~km}$, flow is still cyclonic around the storm center in the upper levels [20]. A distant interaction occurs when an upper positive PV maximum is between $400 \mathrm{~km}$ and $1000 \mathrm{~km}$ from the TC center. In this situation, flow is typically anticyclonic in the upper levels. No trough interaction is considered to occur when an upper PV maximum is at a distance greater than $1000 \mathrm{~km}$. They found $78 \%$ of TCs with a superposition and $61 \%$ of TCs with a distant interaction deepened. In superposition cases, the composite showed that a small-scale upper PV anomaly approached the TC center and dissipated before crossing the TC center, similar to the results of Molinari et al. $[16,17]$. Kimball and Evans [7] simulated idealized cases of a hurricane interacting with four different types of upperlevel troughs in conditions of relatively weak environmental vertical wind shear. Their simulation results show that the hurricane interacting with the strongest trough (largest PV) becomes the most intense while a weaker trough is advected away by the storm and dissipates sooner. All hurricanes interacting with troughs evolve to be larger and stronger, but less intense than hurricanes intensifying in vertical wind shear alone.
The third aspect is the distribution of precipitation before and after landfall. The distribution of precipitation induced by TCs varies in TC size and intensity (e.g., $[1,8,21,22])$. TC size has been found to be sensitive to environmental humidity; Hill and Lackmann [21] performed four idealized highresolution numerical simulations to test the sensitivity of TC size to environmental humidity. Their results indicated that moist environments favor the development of larger TCs, with progressively larger storms evident with each incremental relative humidity $(\mathrm{RH})$. Although moister environment did not show heavier eyewall precipitation or a more intense cyclonic PV tower, more precipitation in outer rainbands occurred in the high-humidity environment. Matyas [22] studied 31 US hurricane landfalls. Her results showed that hurricanes, which did not become extratropical, were the most symmetrically shaped at the time of landfall, while those within 2 days of becoming extratropical were the most asymmetrical. Although the edges of the rain fields did not precisely align with any of the measures of storm size, they were most closely colocated with the radius of gale-force winds in each quadrant.

When Hurricane Floyd (1999) transitioned into an extratropical cyclone, it produced heavy rainfall farther away from the circulation center but also on the left side of the track $[1,3]$. During ET, the environment surrounding the hurricane becomes baroclinic and isentropic ascent occurs near the steep thermal gradient between tropical and continental air masses typically located north of the storm's center, enhancing precipitation in this region (e.g., $[8,23])$. Besides the interaction of Floyd with an upper-level trough, the Appalachians and the coastal terrain played a secondary role in the devastating flooding for this particular event (e.g., [4, 24]). Colle [4] studied high-resolution numerical simulations of Floyd after interaction with the mid-latitude trough and found that without evaporative effects from precipitation a low-level front was $10 \%-20 \%$ weaker than the control and Floyd's central pressure was about $4 \mathrm{hPa}$ weaker. Another simulation without surface heat fluxes resulted in a $4-5 \mathrm{hPa}$ weaker cyclone, and 20\%-30\% less precipitation shifted $100-$ $150 \mathrm{~km}$ farther eastward than the control.

Despite extensive studies of the influences of a diverse set of physical processes (trough-hurricane interaction, environmental moisture, distribution of precipitation in different situations, surface heat fluxes, and coastal terrain), quantitative analysis has rarely been conducted to understand the role of the atmospheric environment in intensifying precipitation carried by hurricanes such as Hurricane Floyd. Specific questions include the following: how much of a role did the midlatitute trough play in the entire life cycle of Floyd, and what percentage of precipitation was exclusively due to the mid-latitude trough? As being described in Tang et al. [5], the hurricane-induced flooding in a coastal watershed is caused by a combination of (1) the previous rainfall event, through antecedent soil moisture and increases in ground water level, (2) precipitation from the interaction of the synoptic environment (trough/ridge) and landfalling hurricane, and (3) a storm surge from the ocean induced by strong hurricane winds. The role of preexisting rainfall associated with Hurricane Dennis in the total flooding during Floyd's 


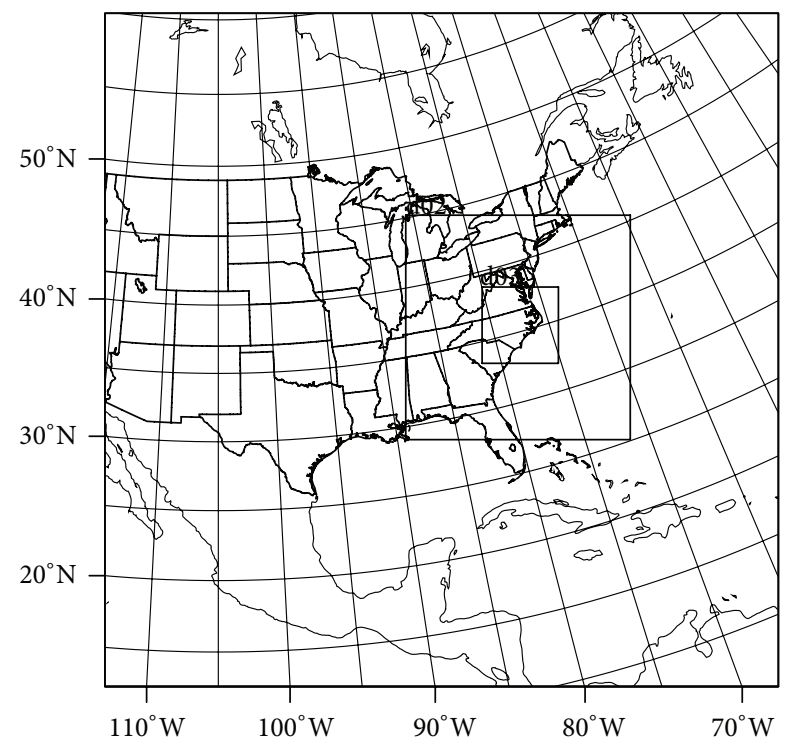

FIgURE 1: Triple-nested WRF model domains.

landfall has been studied by Tang et al. [5], and the results indicated that total runoff would be reduced by $37 \%$ without preexisting rainfall. In this study, we now try to separate the rainfall contribution from Hurricane Floyd and its synoptic environment and quantify the river discharge contributed by the latter alone.

\section{Models, Data, Methods, and Experiments}

2.1. Models and Data. In this study, two models are employed: one is the Weather Research and Forecasting (WRF) model $[25,26]$. It features a fully compressible, Eulerian and nonhydrostatic control equation set. The model uses the Arakawa-C grid and the terrain-following, hydrostatic-pressure vertical coordinate system with the top of the model being a constant pressure surface. The time integration scheme is the thirdorder Runge-Kutta scheme, and second through sixth-order advection schemes are available for the spatial discretization. WRF incorporates various physical processes including microphysics, cumulus parameterization, planetary boundary layer (PBL), surface layer, land-surface, and longwave and shortwave radiations, with several options available for each process. More details about the WRF model are referred to by Wang et al. [26].

WRF version 3.1 is utilized to simulate Hurricane Floyd's landfall in North Carolina during September 15-18 1999. Figure 1 shows the triple-nested WRF model domains used in this study. All domains have $301 \times 301$ horizontal grid meshes. The innermost domain with a $2 \mathrm{~km}$ grid spacing lies within an intermediate domain with a $6 \mathrm{~km}$ grid spacing, which is nested in the outermost domain with an $18 \mathrm{~km}$ grid spacing. It should be noted that the two nested domains are stationary with the innermost high-resolution domain covering the watershed area of interest, the Tar-Pamlico River Basin (Figure 2), which experienced heavy rainfall during the landfall of Floyd. The outermost domain covers most of the US continent and includes the area covered by the mid-latitude trough/ridge. The model top was set at $100 \mathrm{mb}$. Thirty-one unevenly spaced full-sigma levels were used in the vertical, with the maximum resolution in the boundary layer. Fiveminute averaged terrain and landuse data were interpolated to the $18 \mathrm{~km}$ model grids. For the 6 and $2 \mathrm{~km}$ domains, 2 minute and 30-second topography and landuse datasets were interpolated to the grid in order to better resolve the inland hills and valleys. The model simulated precipitation on the innermost domain over the study watershed area is extracted every 6 grid points with a resolution of $12 \mathrm{~km}$ (see the black crosses in Figure 2(a)) to drive the hydrological model.

The other model is a hydrological model-the Annualized Agricultural Nonpoint Source Pollution Model (AnnAGNPS, [27]). AnnAGNPS is a geographic information system- (GIS-) driven watershed hydrology and water quality model developed by the United States Department of Agriculture (USDA). It is a batch process, continuous-simulation, surface-runoff, pollutant loading model, which can simulate loadings of daily river discharge, peak runoff, and nonpoint source pollutants. It has been widely applied in the United States and many other countries. The AnnAGNPS is selected in the study to simulate the hydrograph of a subarea for the upper reaches of the Tar-Pamlico River Basin located above the USGS gage station at Tarboro. This watershed area with its outlet at Tarboro covers an area of $5605 \mathrm{~km}^{2}$. As the AnnAGNPS model is a distributed model, a digital elevation model has been applied to the model and created 1035 irregular cells depending on the height and aspect of each cell (Figure 2(b)). This study area was further divided into seven subwatersheds as depicted in Figure 2. The elevation of the study area varies from 7 to 240 meters above sea level. The land use types in the study area are dominated by forest and cropland. No large water body is present in the study area. AnnAGNPS requires precipitation to be gridded over the basin or to each cell. Precipitation either from observations at the weather stations or from WRF model outputs is input to the cells of the AnnAGNPS model by interpolation. Detailed description regarding the AnnAGNPS model settings for this watershed area is referred to by Tang et al. [5].

The North American Regional Reanalysis (NARR) dataset is selected to provide initial and lateral boundary conditions to the WRF model. It provides atmospheric variables on 29 pressure levels with about $32 \mathrm{~km}$ grid resolution every three hours. NARR data covers the time period from 1979 to present. The surface and ground observation data are provided by North Carolina State Climate Office and NOAA National Climate Data Center. The stream flow data at each station depicted in Figure 2(b) are obtained from USGS (U. S. Geological Survey). Digital data such as landuse, soil, and digital elevation model (DEM) for the AnnAGNPS model is from North Carolina State University library website.

2.2. Vortex Removal. Bogussing and/or removing a TC from the initial conditions are conducted through the utility program (tc_em.exe). The bogussing program was ported from MM5 for WRF in version 3.1 by Fredrick et al. [28]. In this version of the scheme, one can either introduce a new vortex 


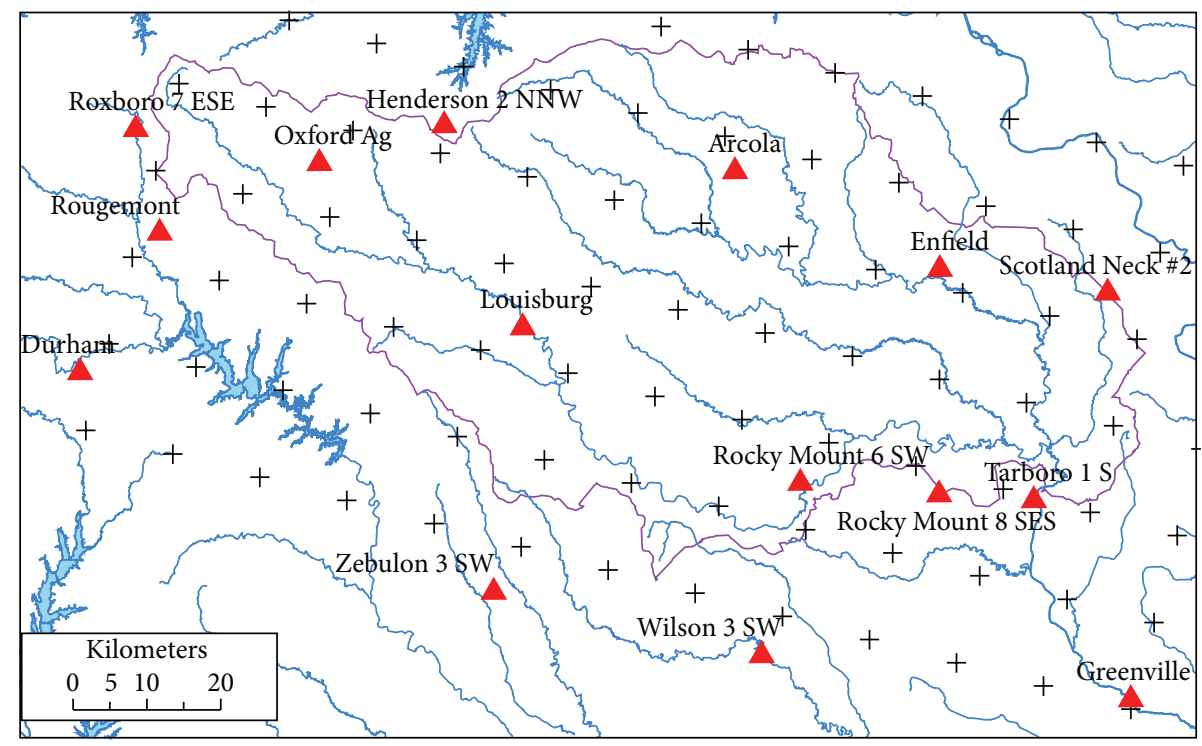

(a)

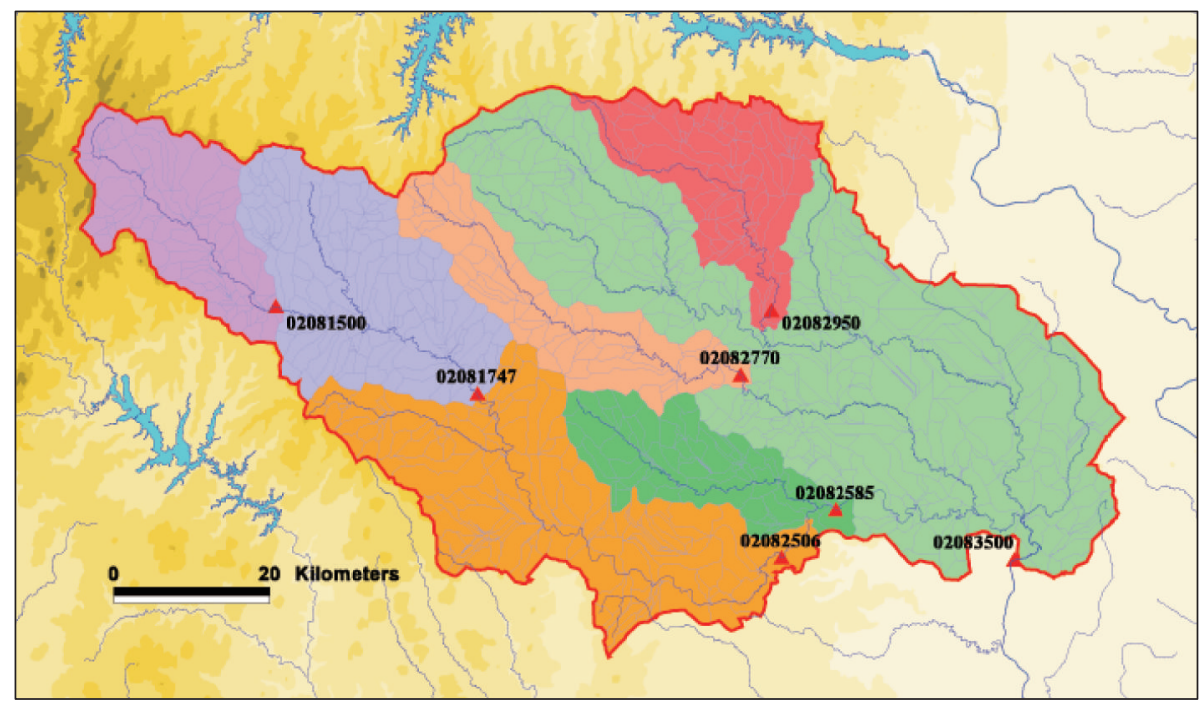

(b)

FIGURE 2: (a) Locations of weather stations (red triangle points) in Tar-Pamlico River Basin and AnnAGNPS model input precipitation points (black crosses) extracted from the innermost WRF model domain every six grid points and (b) USGS stream flow gages (triangle points) and corresponding areas in AnnAGNPS in Tar-Pamlico River Basin (each downstream gage area covers all upper gage areas).

or remove an existing vortex. The input to the scheme is a single file containing fields on isobaric surfaces that have been produced by the WRF preprocessing system (WPS). In order to isolate the role of large-scale synoptic environment, the vortex associated with Hurricane Floyd is removed by using this technique.

According to Fredrick et al. [28], the vortex removal scheme starts by searching for the vortex corresponding to the storm in the first guess field. This is done by looking for the maximum relative vorticity within a prescribed radial distance from the best track location of the TC. A $400 \mathrm{~km}$ searching radius is currently used in this study. The grid point where the maximum vorticity is located serves as the center of vortex to be removed. Once the vortex has been found, the first-guess vorticity and divergence within $600 \mathrm{~km}$ radius of the first guess storm are removed, and then the velocity is recalculated. The relationship of the vorticity is as follows:

$$
\nabla^{2} \psi=\zeta
$$

where $\psi$ is the stream function for the nondivergent wind and $\zeta$ is the relative vorticity. To define the nondivergent wind associated with the first-guess storm, the vorticity is set to 0 outside a radius of $600 \mathrm{~km}$. The Dirichlet boundary conditions stream function is defined to be 0 and the successive overrelaxation (SOR) method is used to solve (1) for the perturbation stream function on all pressure surfaces. 


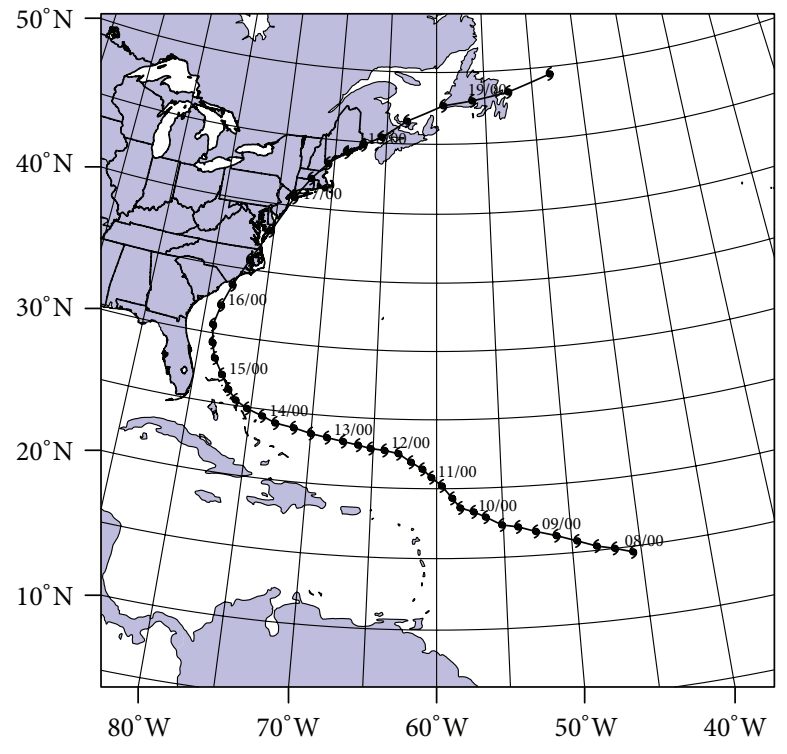

(a)

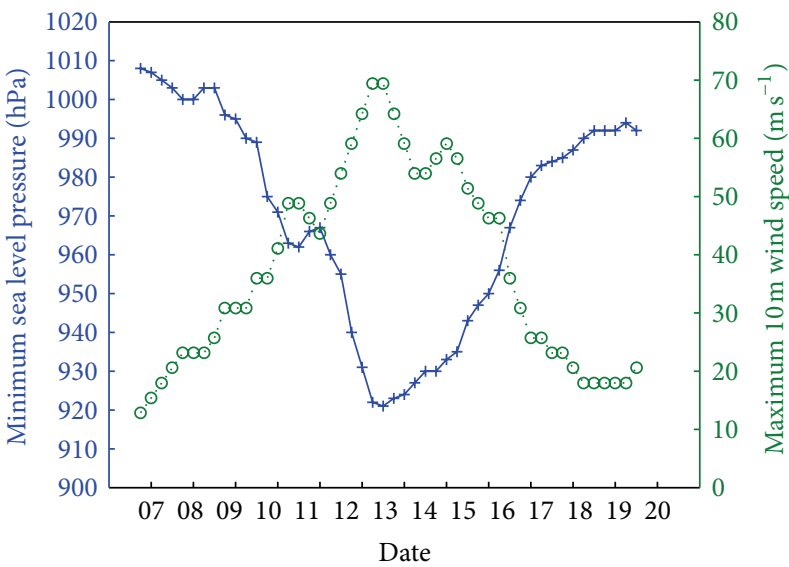

(b)

FIGURE 3: Track (a) and intensity (b), including minimum sea level pressure and maximum $10 \mathrm{~m}$ wind, of Hurricane Floyd according to the best track data from NHC.

The nondivergent wind $v_{\psi}$ is then calculated from the following relationship:

$$
v_{\psi}=\widehat{k} \times \nabla \psi
$$

Once the nondivergent wind is calculated, it is subtracted from the first-guess wind fields. Removal of the divergent wind from the first-guess storm is similar. After divergent winds are removed, the geopotential height and temperature anomalies from the first-guess field are also removed, with the surface and sea level pressure perturbations being updated accordingly. More detailed information regarding the vortex removal technique is referred to by Fredrick et al. [28].

The configuration for removing the vortex associated with Hurricane Floyd is set as follows: the center location of Hurricane Floyd at 1500 UTC on September 15, 1999 is at $27.1^{\circ} \mathrm{N}$ and $77.7^{\circ} \mathrm{W}$ according to the best track data from the National Hurricane Center. The maximum observed sustained wind speed was $59.16 \mathrm{~m} \mathrm{~s}^{-1}$. The radius of maximum wind is set to $90 \mathrm{~km}$.

2.3. Experiment Design. In order to investigate the impact of large-scale synoptic environment, two simulations were conducted: the control (CTRL) simulation and synoptic environment (ENV) simulation. All configurations were the same except that the CTRL experiment has Hurricane Floyd while the ENV experiment has the vortex associated with Hurricane Floyd removed at the initial time.

Both simulations choose the explicit WSM 6-class microphysics scheme [29] which includes prognostic equations for cloud ice and water, snow, rain, and graupel processes suitable for high-resolution simulations. The Mellor-Yamada Nakanishi Niino (MYNN) level 2.5 planetary boundary layer (PBL) scheme [30], the MYNN Monin-Obukhov similarity theory surface scheme corresponding to MYNN-PBL scheme, the Rapid Radiative Transfer Model (RRTM) longwave [31] radiation scheme, and the Dudhia shortwave radiation scheme [32] were chosen for all the three domains, whereas the KainFritsch cumulus scheme [33] was only specified for outermost domain.

In order to match the period of daily rainfall observation data, all 1200 UTC to 1200 UTC $24 \mathrm{hr}$ periods will be referenced by the date upon which the $24 \mathrm{hr}$ period ends. Thus, the accumulation from 1200 UTC September 15, to 1200 UTC September 16, 1999 will be simply known as the $24 \mathrm{hr}$ accumulation for September 16, 1999. The precipitation from WRF model outputs of the CTRL and ENV experiments then served as input data for the AnnAGNPS model to simulate the discharge and total volume of runoff water carried at the outlet of the watershed. Correspondingly, three AnnAGNPS model runs were conducted, by using observational precipitation data at weather observation stations, model simulated precipitation at the model grids from the CTRL experiment, and model simulated precipitation induced by Hurricane Floyd only (obtained by subtracting precipitation of the ENV run from that of the CTRL run under the assumption of linear relationship during the interaction of atmospheric environment and TC), respectively.

\section{Results}

The history of Floyd can be described from the best track position (Figure 3) from the National Hurricane Center. Early stage of Hurricane Floyd started as a tropical wave off the coast of Africa in early September 1999. It traveled across the Atlantic until becoming a tropical depression on September 7, 1999, located at $14.6^{\circ} \mathrm{N}$ and $45.6^{\circ} \mathrm{W}$ with central pressure of 


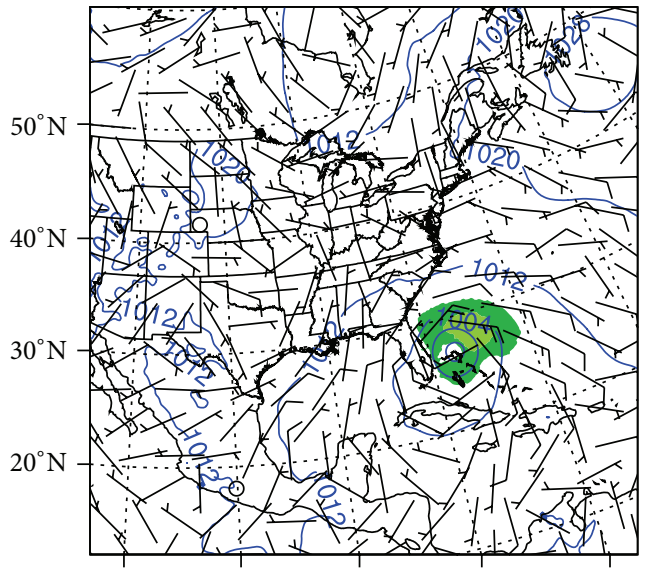

(a)

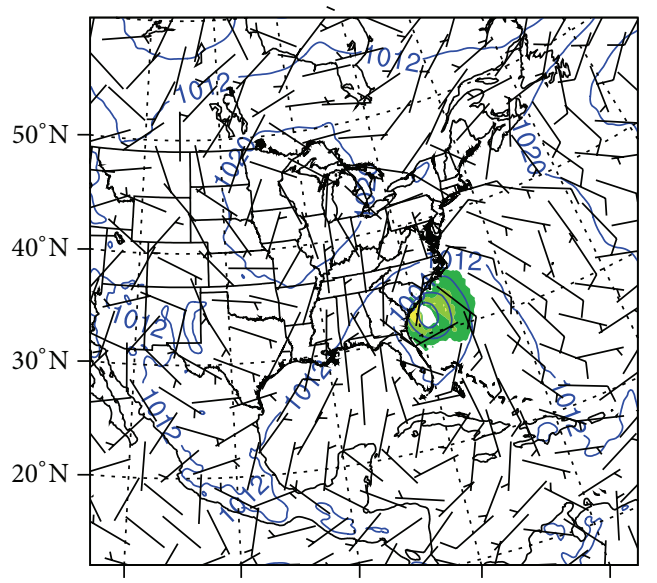

(c)

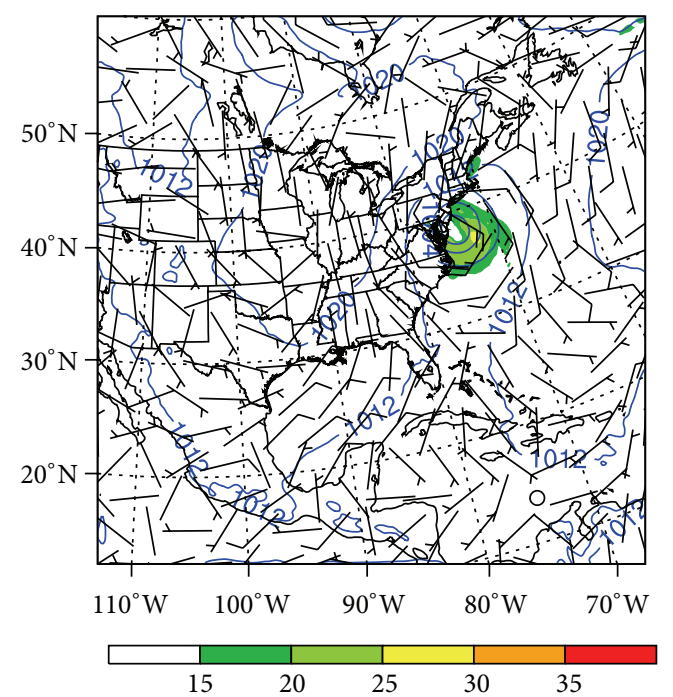

(e)

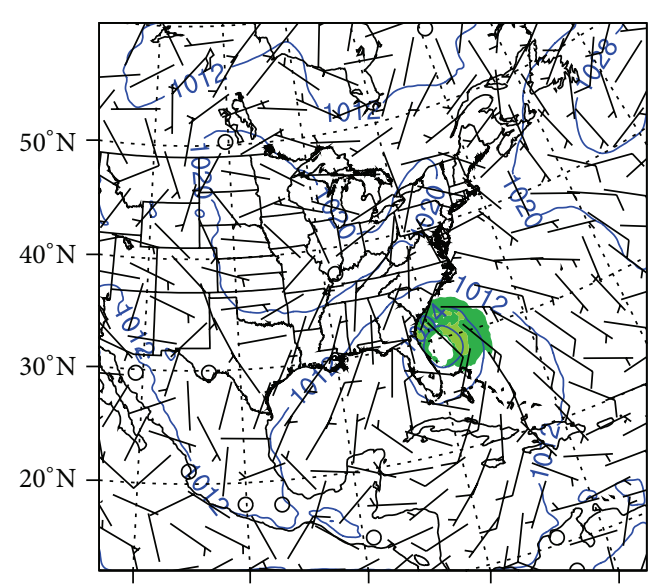

(b)

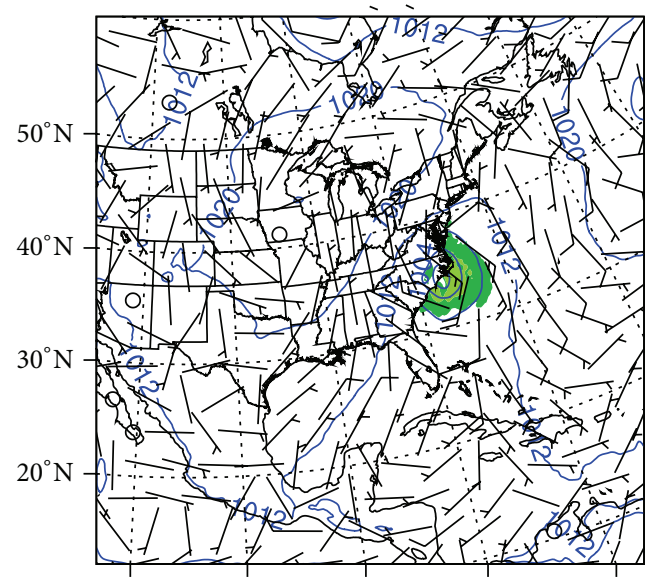

(d)

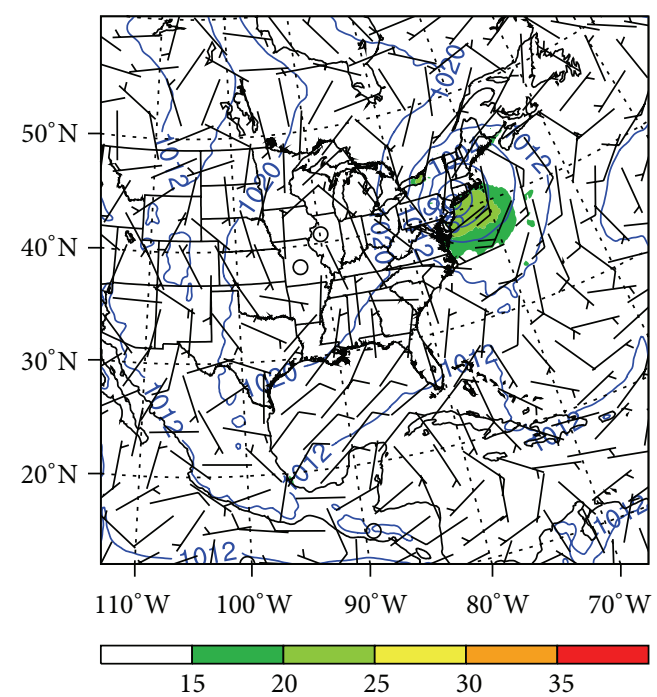

(f)

FIGURE 4: Sea level pressure (contours every $8 \mathrm{hPa}$ ) and $10 \mathrm{~m}$ wind (shaded colors and wind bars with 1 full bar $=5 \mathrm{~m} \mathrm{~s}^{-1}$ ) from the CTRL experiment in every 12 hours: (a) 00Z 15 Sept. 1999, (b) 12Z September 15, 1999, (c) 00Z September 16, 1999, (d) 12Z September 16, 1999, (e) 00Z September 17, 1999, and (f) 12Z September 17, 1999. 
$1008 \mathrm{hPa}$ and wind speed of $13 \mathrm{~m} \mathrm{~s}^{-1}$ [34]. At 06Z September 8 , it was upgraded to a tropical storm (TS) with central pressure of $1005 \mathrm{hPa}$ and wind speed up to $18 \mathrm{~m} \mathrm{~s}^{-1}$. By the time of $12 \mathrm{Z}$ September 10, approximately $370 \mathrm{~km}$ northeast of the Leeward Islands, Floyd was upgraded into hurricane status with central pressure of $989 \mathrm{hPa}$ and wind speed up to $36 \mathrm{~m} \mathrm{~s}^{-1}$.

As Floyd moved westward, it reached its maximum strength on September 13, with a minimum central pressure of $921 \mathrm{hPa}$ and a maximum sustained wind up to $69 \mathrm{~m} \mathrm{~s}^{-1}$, making the storm a Category 4 on the Saffir-Simpson Scale. When passing the Bahamas on September 14, Floyd began to move northwest due to the influence of a large upper midtrough located in Ontario, Canada [34].

The WRF simulations in this study cover the period from $00 Z$ September 15, to $12 Z$ September 17, and the results are described as below. After $12 Z$ September 17, Floyd moved from Maine toward the northeast and then east-northeast and soon dissipated after September 18, which is out of interest for this study.

3.1. Control Simulation and Synoptic Features of Hurricane Floyd. Figure 4 displays the sea level pressure and $10 \mathrm{~m}$ wind for the outermost domain from the CTRL simulation every 12 hours from 00Z September 15, to 12Z September 17, 1999. These plots clearly depict the track Hurricane Floyd from near coastal Florida to Maine. Floyd continued to turn gradually to the north during the time of $00 \mathrm{Z}$ to $12 \mathrm{Z}$ September 15 , (Figures 4(a) and 4(b)). The center of the hurricane was moving parallel to the eastern Florida coast till 12Z September 15. Figure 4(c) is similar to the manual surface analysis map from Colle ([4], see his Figure 1(a)) in the terms of the central location of Floyd (about $200 \mathrm{~km}$ south of North Carolina) and the pressure field at $00 \mathrm{Z}$ September 16 . The differences are the former has a greater central pressure ( 980 versus $951 \mathrm{hPa}$ ) and smaller maximum wind ( 25 versus $59 \mathrm{~m} \mathrm{~s}^{-1}$ ). This is probably due to the higher central pressure and lower maximum wind from NARR data at the initial time 00Z September 15 , as well as to the relatively low resolution (with a $18 \mathrm{~km}$ grid spacing) of the outermost domain. Figure 5 depicts the $500 \mathrm{hPa}$ potential vorticity and geopotential height from the CTRL simulation in $12 \mathrm{~h}$ increments. The large upper midlatitude trough can be seen at $500 \mathrm{hPa}$ from Figure 5(a) at 00Z September 15. At 00Z September 16 (Figure 5(c)), Floyd began to interact with a broad baroclinic zone that extended along the coast of the southeastern and mid-Atlantic states. The $500 \mathrm{hPa}$ geopotential height agrees well with the NCEP analysis in Colle ([4], see his Figure 1(b)), with both Floyd and the mid-latitude trough in very similar places.

Floyd made landfall at Bald Head Island, NC at 0630Z September 16. Although the central pressure of Floyd gradually weakened after September 13, the potential vorticity of center at $500 \mathrm{hPa}$ (Figure 5) increased from 3.5 PVU at $00 \mathrm{Z}$ September 15 to $4 \mathrm{PVU}$ at $12 \mathrm{Z}$ September 15 and up to $4.5 \mathrm{PVU}$ at $00 \mathrm{Z}$ September 16, and $12 \mathrm{Z}$ September 16, $\left(1 \mathrm{PVU}=10^{-6} \mathrm{~K} \mathrm{~kg}^{-1} \mathrm{~m}^{2} \mathrm{~s}^{-1}\right)$. The trough to the northwest gradually deepened and moved southeastward while Floyd continued moving northward until the two systems merged at $12 \mathrm{Z}$ September 16, (Figure 5(d)). By 00Z September 17, (Figure 5(e)), the two systems completely merged with each other, and Floyd had made extratropical transition (ET). At $12 \mathrm{Z}$ September 17, Floyd had weakened to $984 \mathrm{hPa}$ from observation along the northern New England. The area of PV greater than 1.5 PVU became larger, and the merged extratropical cyclone moved toward the northeast, although the maximum PV at the center of the extratropical cyclone weakened to 3.5-4 PVU. The heaviest rainfall occurred during this ET period of $12 \mathrm{Z} 16-12 \mathrm{Z}$ September 17. Although the pressure field weakened, the PV field did increase after landfall during ET due to the interaction of the trough and Floyd. Colle [4] proved that the surface temperature gradient to the north of the cyclone center had doubled in magnitude from $12 Z$ September 16 to $00 Z$ September 17 although surface pressure was slightly weakened. The combined effects of an intensified baroclinic zone in this period are consistent with the view point of Atallah and Bosart [3]. But this intensification was not as strong as some other documented ET events (e.g., $[12,23]$ ) which featured both a pressure decrease and a temperature gradient increase. Floyd further weakened to $992 \mathrm{hPa}$ by $12 \mathrm{Z}$ September 18, and maintained this intensity for the next $24 \mathrm{~h}$ [34].

\subsection{Precipitation Distribution of Floyd from the Control Simu-} lation. The comparison of the model simulated precipitation with the observation is shown in Figure 6. The precipitation of the control run in the innermost domain (Figure 6(b)) is comparable to the NOAA observed result (Figure 6(a)). The color scheme of NOAA map has been modified for comparison purposes. The original map can be found in Pasch et al.s work [34]. It should be noted that the time period of NOAA observed precipitation was accumulated from 14 September to September 19, 1999 while the WRF model result only accounts for the period from 00Z 15 September to $12 Z$ September 17. However, most rainfall in North Carolina during this event occurred in the time frame. It is obvious that the pattern of accumulated rainfall is very similar, except that the highest rainfall area in the CTRL simulation is located in South Carolina rather than North Carolina as observed and that the area with rainfall over $380 \mathrm{~mm}$ is smaller than the observed one. After making landfall in South Carolina and moving north to North Carolina, the heavy precipitation fell from the coast to the central piedmont region up to the Appalachian Mountains in the west as demonstrated. The accumulated precipitation pattern of Floyd is highlighted by a linear northeast and southwest axis.

To examine the accumulated precipitation from $12 \mathrm{Z} \mathrm{Sep-}$ tember 15 to $12 \mathrm{Z}$ September 17 at the watershed area, Figure 9 compares the simulated precipitations from the CTRL run in all the three domains with observations at selected weather stations. Distribution of these stations can be found in Figure 2. Stations in the chart listed from left to right are in the order from upper to lower watershed (which also means from west to east). As two-way nesting was utilized for domain nesting, there are no significant differences among the simulated results for the three model domains. In the upper watershed, the simulated precipitation is lower than 


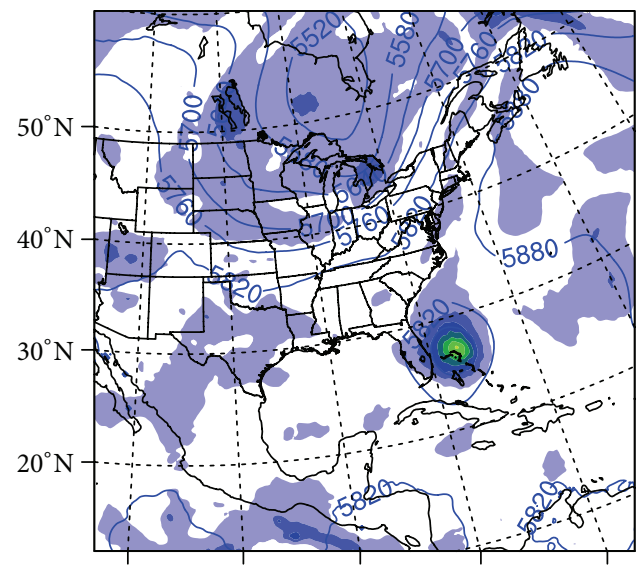

(a)

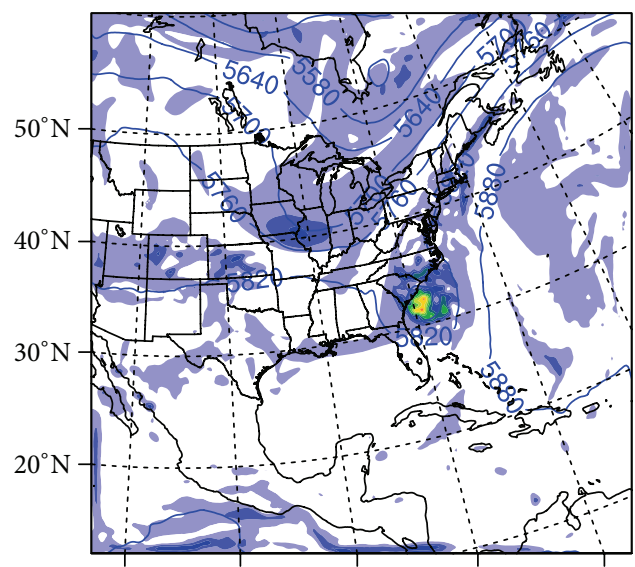

(c)

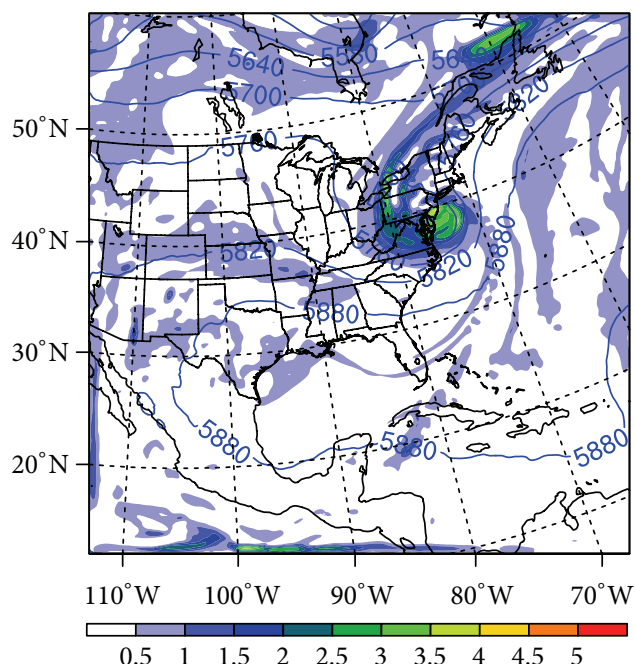

(e)

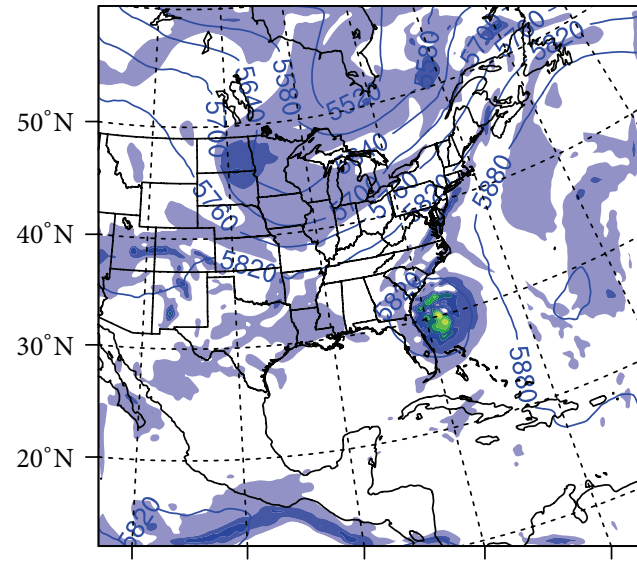

(b)

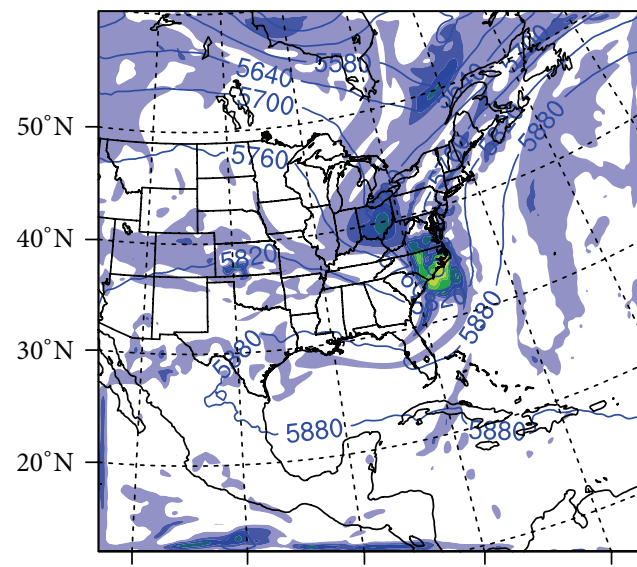

(d)

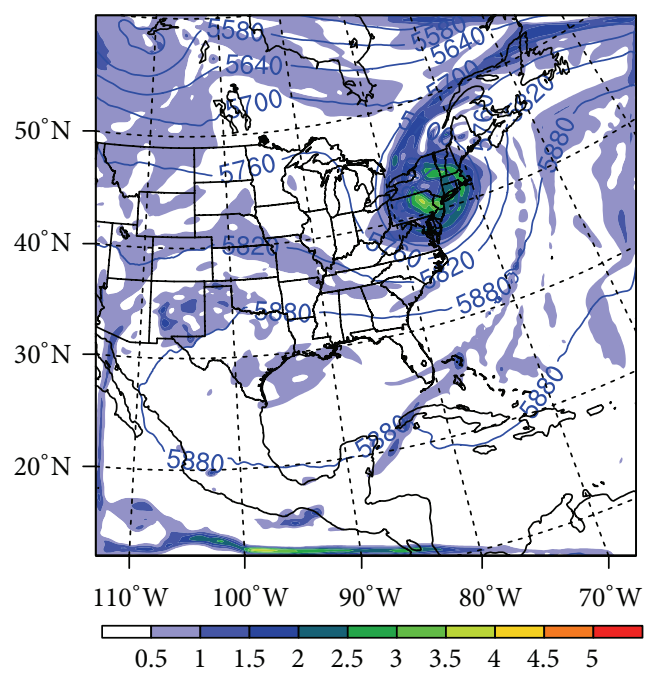

(f)

FIGURE 5: $500 \mathrm{hPa}$ potential vorticity (shaded in every $0.5 \mathrm{PVU}, 1 \mathrm{PVU}=10^{-6} \mathrm{~K} \mathrm{~kg}^{-1} \mathrm{~m}^{2} \mathrm{~s}^{-1}$ ) and geopotential height (blue contours every $60 \mathrm{~m}$ ) from the CTRL experiment in every 12 hours: (a) 00Z September 15, 1999, (b) 12Z September 15, 1999, (c) 00Z September 16, 1999, (d) $12 Z$ September 16, 1999, (e) 00Z September 17, 1999, and (f) 12Z September 17, 1999. 


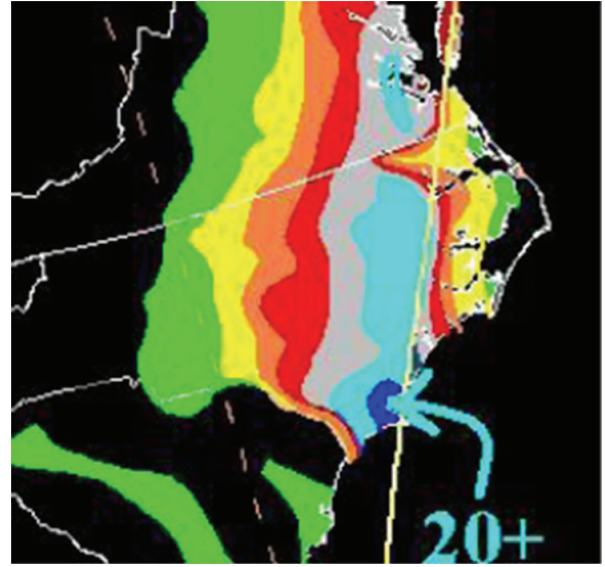

(a)

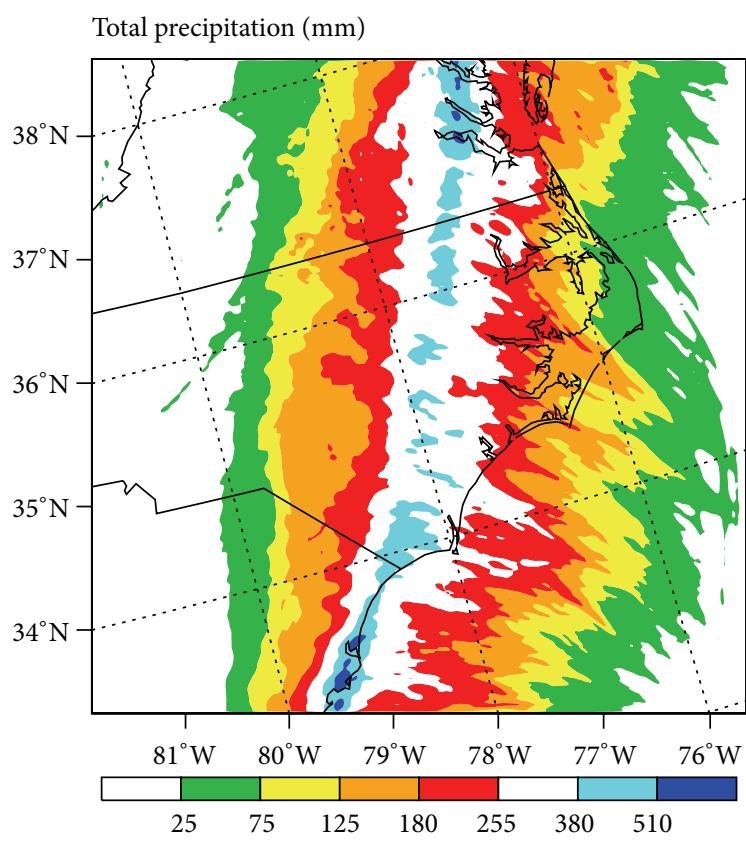

(b)

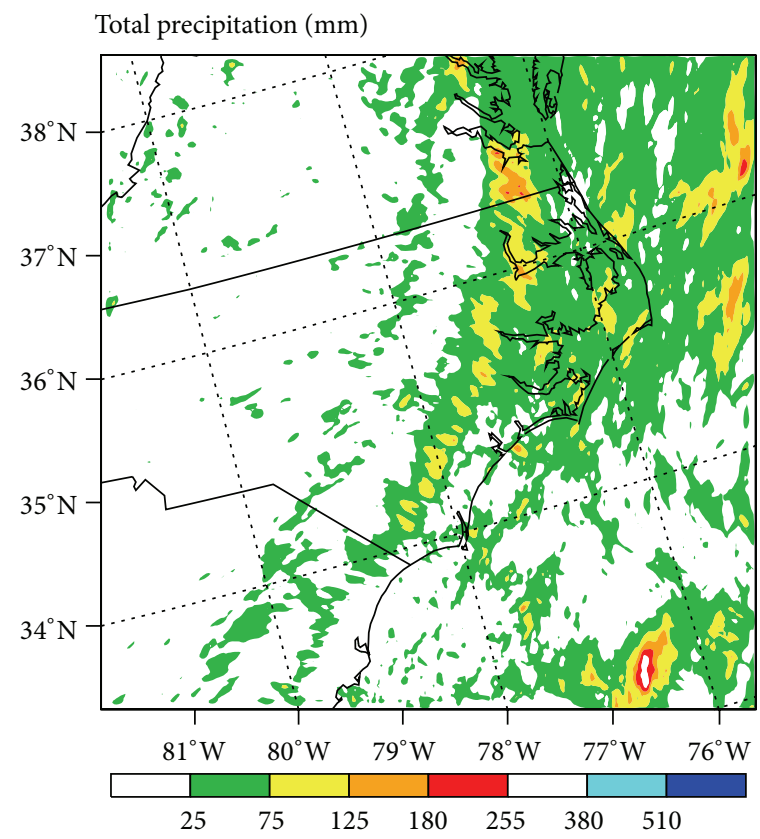

(c)

Figure 6: (a) Accumulated precipitation during Hurricane Floyd landfall from Sep, 14 to 191999 from NOAA observed precipitation map (with modified color scheme) in which the yellow line indicates the track of Floyd, (b) accumulated precipitation from the CTRL simulation, and (c) accumulated precipitation from the ENV simulation. Blue is $510 \mathrm{~mm}$; cyan is $380 \mathrm{~mm}$; gray is $255 \mathrm{~mm}$; Red is $180 \mathrm{~mm}$; orange is $125 \mathrm{~mm}$; yellow is $75 \mathrm{~mm}$ and green is $25 \mathrm{~mm}$ (modified color scheme from NOAA).

the observed for stations such as Roxboro 7 ESE, Roughment, and Oxford AG, while the simulated precipitation is higher than observed in some lower parts of the watershed. Overall, the model simulated precipitations are close to the observations, with the differences less than $30 \%$ for all the stations except the Scotland Neck No. 2 station. And five out of thirteen stations have differences between simulated and observed precipitation less than $10 \%$ for domain 1 . More details regarding the comparison between the simulated precipitation from the CTRL run and the observed precipitation for each weather station are listed in Table 1.

3.3. Comparison of Precipitation from TC Vortex Removal with CTRL. Figure 7 shows sea level pressure and $10 \mathrm{~m}$ wind 


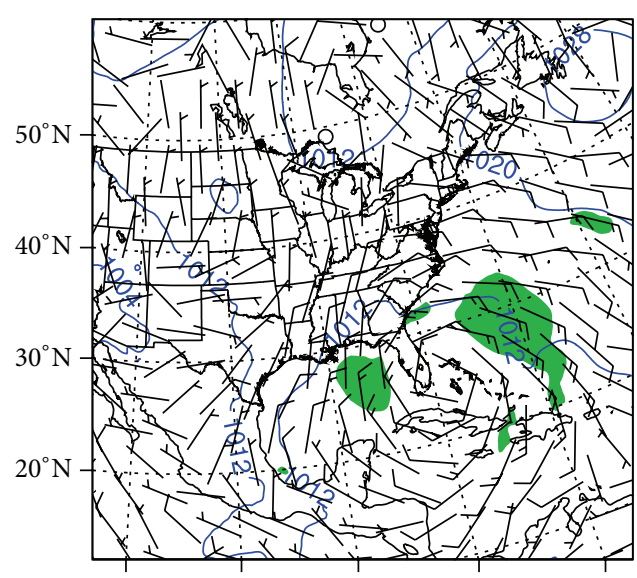

(a)

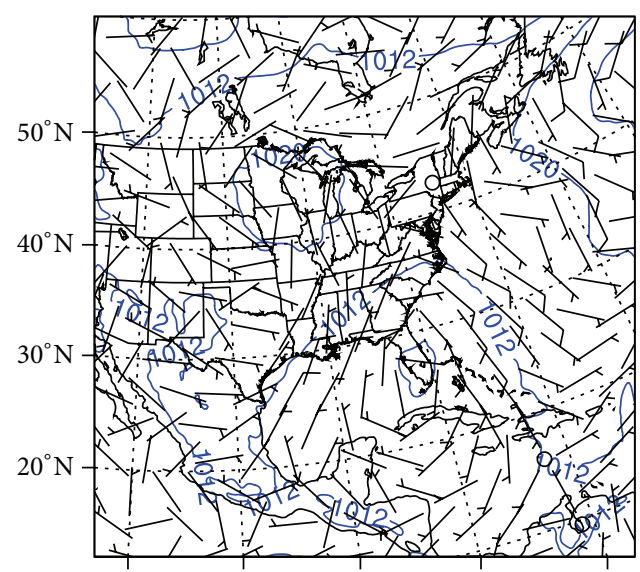

(c)

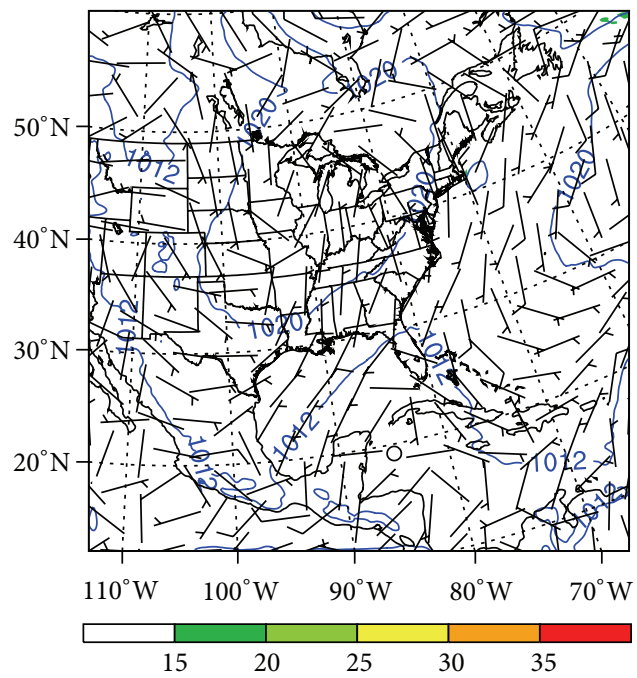

(e)

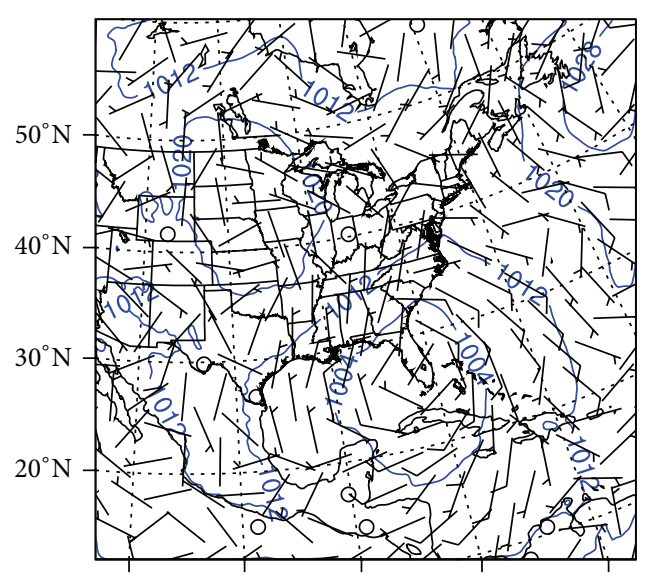

(b)

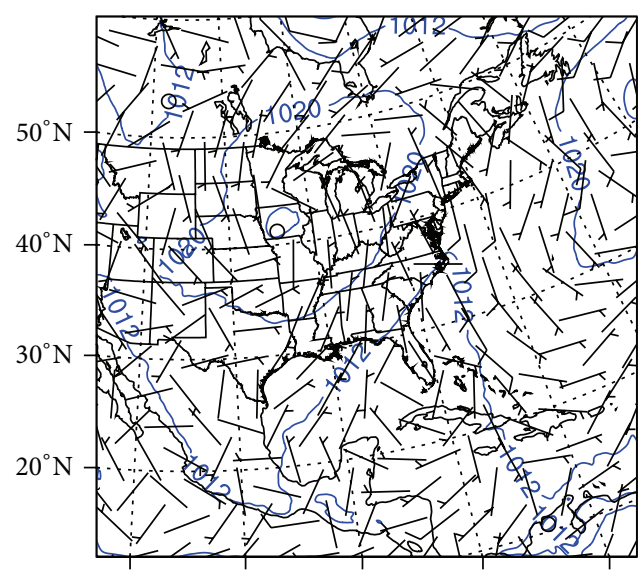

(d)

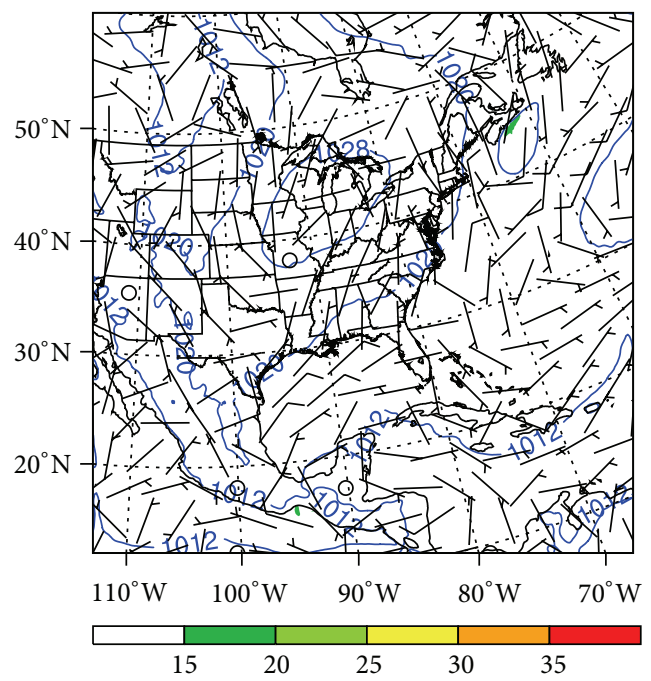

(f)

FIgURE 7: The same as Figure 4 but for the ENV experiment.

from the ENV simulation in every 12 hours. Compared with Figure 4, Floyd has been removed from pressure field, although there is still a cyclonic circulation existing to the south of the Carolinas. This might be due to the large size of the vortex. Vortex removal may not cleanly eliminate the effects from surrounding environment. However, this remaining circulation did not move northward like Floyd and disappeared gradually (Figure 7). Thus, in the ENV run the remaining circulation would have no significant impact on the precipitation over the watershed of interest in this study. 


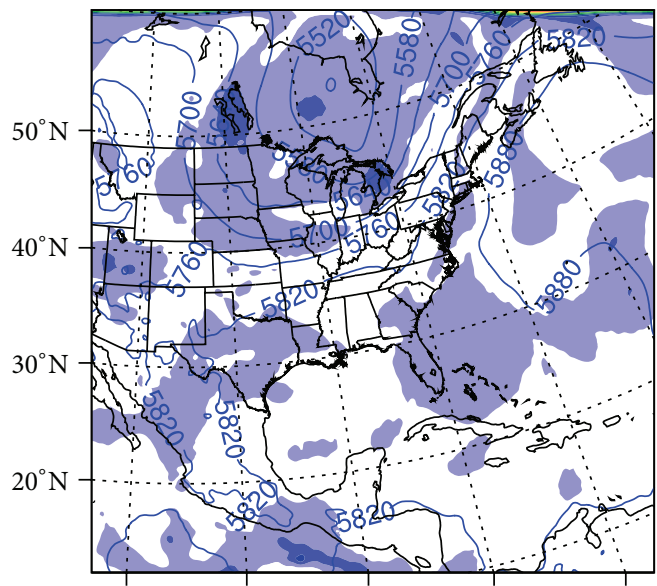

(a)

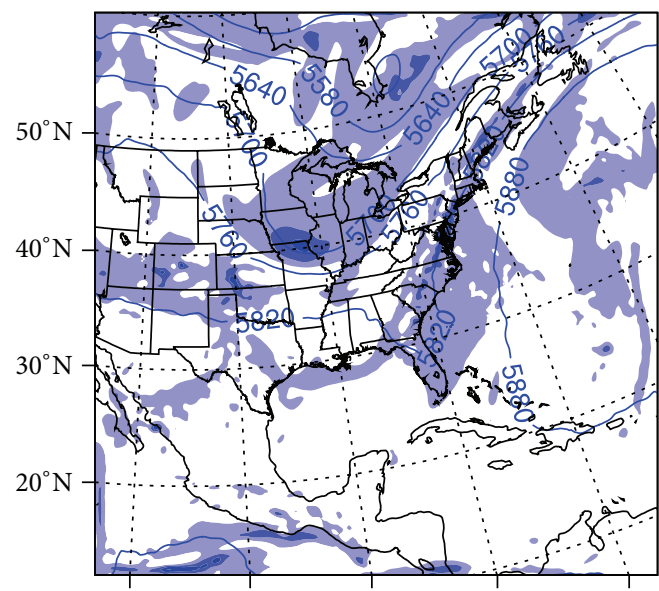

(c)

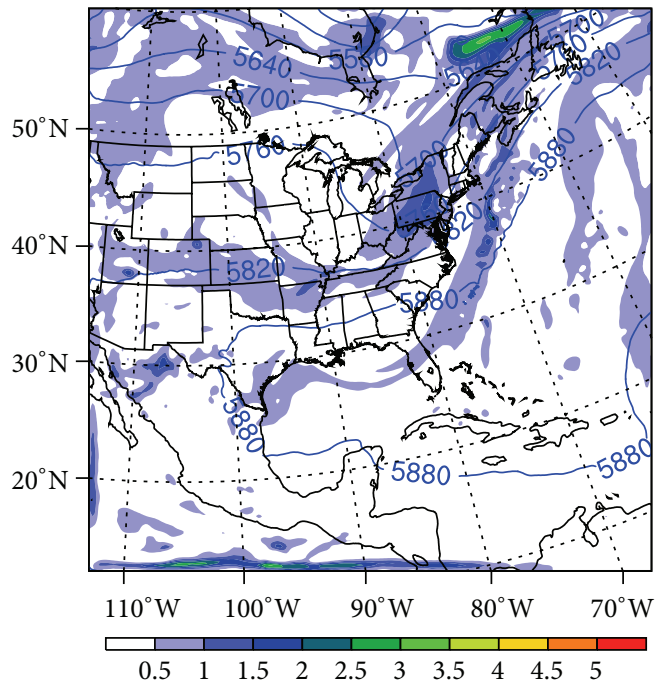

(e)

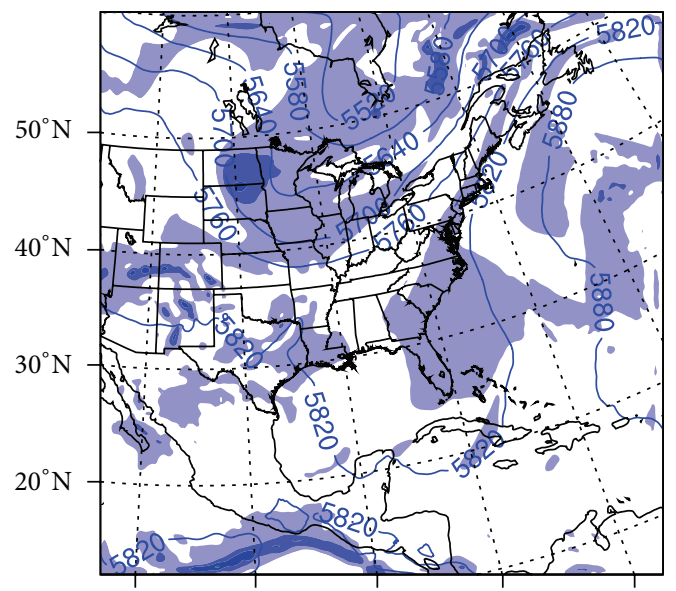

(b)

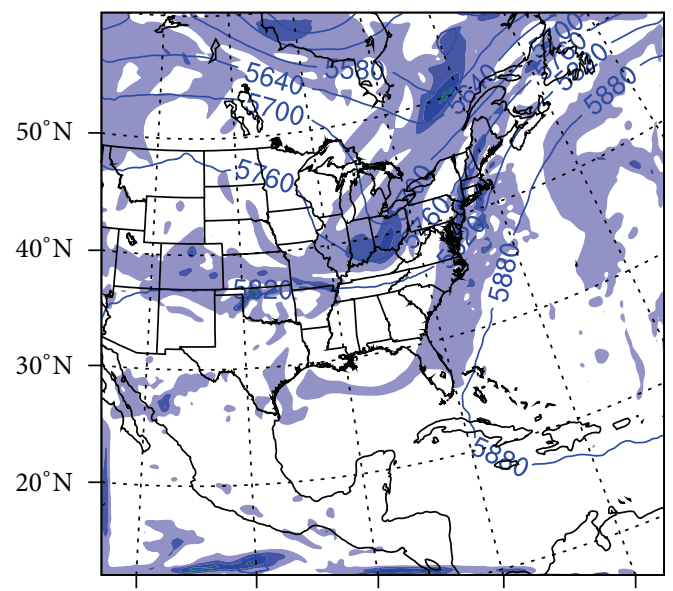

(d)

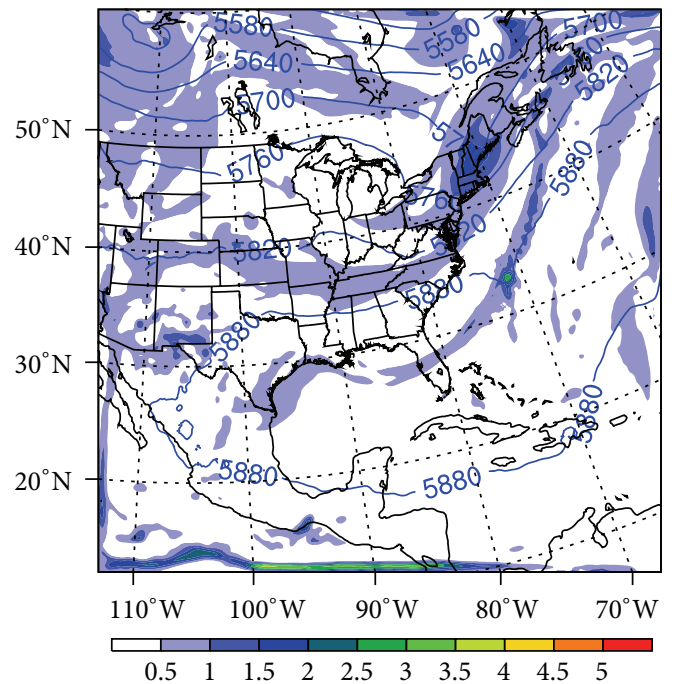

(f)

FIgURE 8: The same as Figure 5 but from the ENV experiment. 
TABLE 1: The observed and the CTRL experiment simulated total precipitations (in mm) on September 16 and 17, 1999 at the weather stations. Differences in percentage between the simulated and observed precipitation are also given.

\begin{tabular}{|c|c|c|c|c|c|c|c|c|c|c|}
\hline \multirow[t]{2}{*}{ Station name } & \multirow[t]{2}{*}{ Station ID } & \multirow[t]{2}{*}{ Latitude } & \multirow[t]{2}{*}{ Longitude } & \multirow{2}{*}{$\begin{array}{l}\text { Observed total } \\
\text { precipitation } \\
(\mathrm{mm})\end{array}$} & \multicolumn{3}{|c|}{ Simulated total precipitation $(\mathrm{mm})$} & \multicolumn{3}{|c|}{$\begin{array}{l}\text { Differences between simulated } \\
\text { and observed total } \\
\text { precipitations (\%) }\end{array}$} \\
\hline & & & & & Domain 1 & Domain 2 & Domain 3 & Domain 1 & Domain 2 & Domain 3 \\
\hline Arcola & 310241 & 36.29 & -77.98 & 224 & 225 & 244 & 251 & 1 & 9 & 12 \\
\hline Enfield & 312827 & 36.17 & -77.68 & 259 & 310 & 321 & 323 & 20 & 24 & 25 \\
\hline Greenville & 313638 & 35.64 & -77.40 & 314 & 318 & 307 & 312 & 1 & -2 & -1 \\
\hline Henderson 2 NNW & 313969 & 36.35 & -78.41 & 134 & 143 & 152 & 154 & 7 & 14 & 15 \\
\hline Louisburg & 315123 & 36.10 & -78.30 & 204 & 161 & 162 & 161 & -22 & -21 & -21 \\
\hline Oxford AG & 316510 & 36.31 & -78.61 & 138 & 125 & 116 & 117 & -10 & -16 & -15 \\
\hline Roxboro 7 ESE & 317516 & 36.35 & -78.89 & 123 & 92 & 90 & 91 & -25 & -27 & -26 \\
\hline Rougemont & 317499 & 36.22 & -78.85 & 115 & 92 & 98 & 96 & -20 & -15 & -16 \\
\hline Snow Hill 2 SW & 318060 & 35.53 & -77.68 & 387 & 385 & 404 & 386 & -1 & 5 & 0 \\
\hline Scotland Neck No. 2 & 317725 & 36.14 & -77.42 & 277 & 377 & 407 & 409 & 36 & 47 & 48 \\
\hline Williamston $1 \mathrm{E}$ & 319440 & 35.85 & -77.03 & 326 & 292 & 308 & 308 & -11 & -6 & -6 \\
\hline Wilson 3 SW & 319476 & 35.70 & -77.95 & 259 & 253 & 284 & 300 & -2 & 10 & 16 \\
\hline Zebulon 3 SW & 319923 & 35.78 & -78.35 & 237 & 175 & 178 & 189 & -26 & -25 & -20 \\
\hline
\end{tabular}

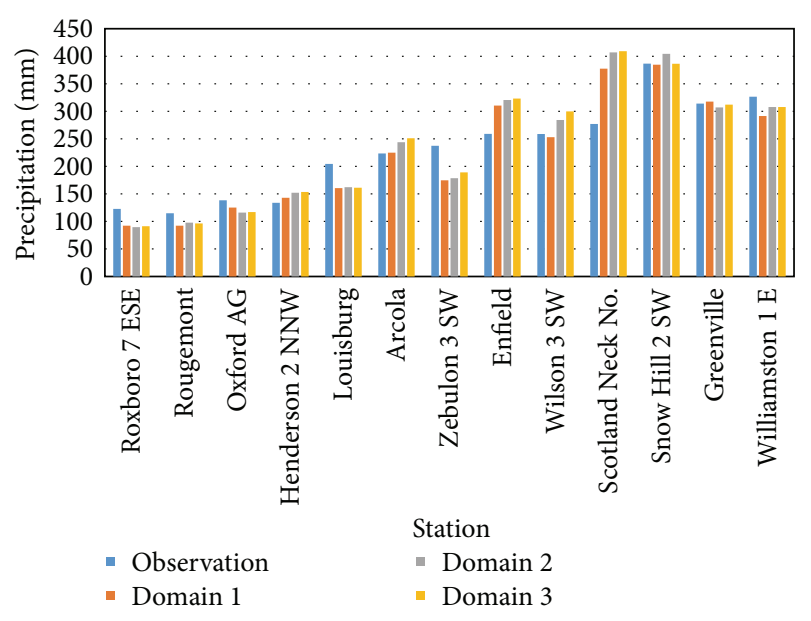

FIGURE 9: Comparison of WRF simulated precipitation in domains 1,2 , and 3 and observation at selected weather stations.

Figure 8 presents potential vorticity and geopotential height every 12 hours at $500 \mathrm{hPa}$ after removing the vortex associated with Floyd at the initial time of 00Z September 15. Without the Floyd vortex, the northwest trough is still located in the same place and geopotential height did not change. At $12 Z$ September 15, in Figure 8(b), the highest PV of 1.5 PVU moved southeastward and was located in eastern Dakotas. These are very similar to those in Figure 5(b) without removing the vortex. This trough continued moving southeastward at $00 \mathrm{Z}$ September 16, and the PV fields are similar to where the 1.5 PVU field was located at the boundary between Iowa and Missouri. Until 12Z September 16, the differences of PV field can be seen clearly with/without Floyd. The area of PV larger than 1.5 PVU expanded and deepened as described in Figures 5(a) and 5(d). However, the 1.5 PVU field without

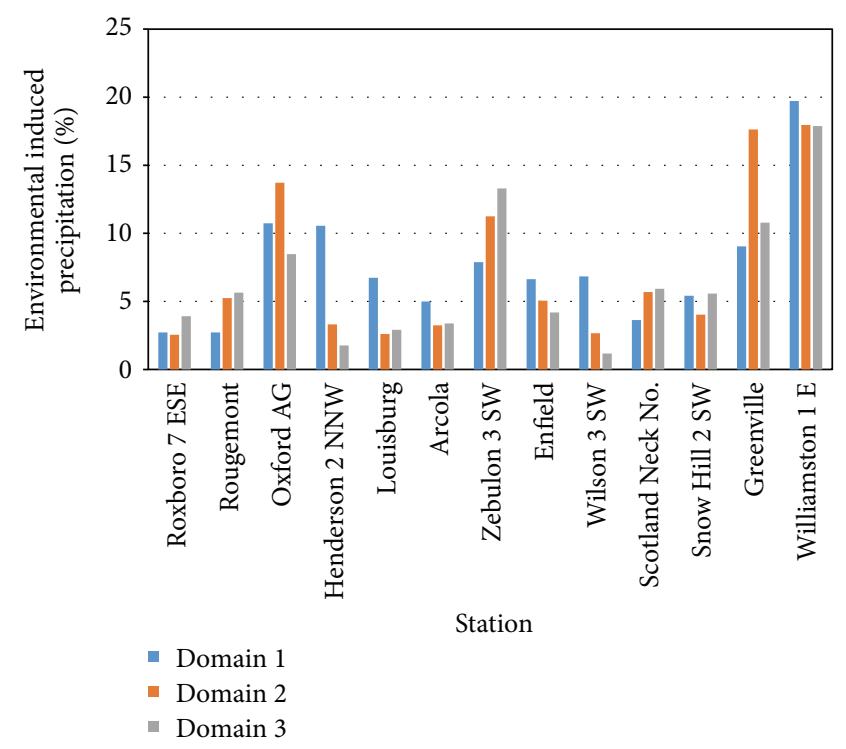

FIGURE 10: Percentages of the ENV experiment simulated precipitation relative to the results of the CTRL experiment in domains 1,2 , and 3 at the weather stations.

Floyd is just shifted to the southeast to Indiana and Ohio with a little expansion but not strengthening. This 1.5 PVU area moves northeastward at 00Z September 17, and further moves to the north at time $12 \mathrm{Z}$ September 17, without strengthening.

The accumulated precipitation from the ENV experiment is shown in Figure 6(c). The environment-only-induced precipitation is mostly distributed along the coastal region. In the study area, there is only a small amount of environmental precipitation while more precipitation is distributed downstream of Tar-Pamlico Sound. There is more precipitation in the northeast than in the west and southwest. Figure 10 
TABLE 2: The ENV experiment simulated total precipitation (in $\mathrm{mm}$ ) on September 16 and 17, 1999 at the weather stations from the three model domains and their percentages relative to the CTRL experiment results.

\begin{tabular}{|c|c|c|c|c|c|c|c|}
\hline \multirow{2}{*}{ Station name } & \multirow{2}{*}{ Station ID } & \multicolumn{3}{|c|}{ Simulated environmental precipitation (mm) } & \multicolumn{3}{|c|}{ Percentage relative to the CTRL experiment results (\%) } \\
\hline & & Domain 1 & Domain 2 & Domain 3 & Domain 1 & Domain 2 & Domain 3 \\
\hline Arcola & 310241 & 11 & 8 & 8 & 5.00 & 3.24 & 3.38 \\
\hline Enfield & 312827 & 21 & 16 & 14 & 6.63 & 5.05 & 4.19 \\
\hline Greenville & 313638 & 29 & 54 & 34 & 9.04 & 17.63 & 10.79 \\
\hline Henderson 2 NNW & 313969 & 15 & 5 & 3 & 10.55 & 3.32 & 1.76 \\
\hline Louisburg & 315123 & 11 & 4 & 5 & 6.74 & 2.61 & 2.92 \\
\hline Oxford AG & 316510 & 13 & 16 & 10 & 10.74 & 13.72 & 8.47 \\
\hline Roxboro 7 ESE & 317516 & 3 & 2 & 4 & 2.72 & 2.55 & 3.91 \\
\hline Rougemont & 317499 & 3 & 5 & 5 & 2.72 & 5.24 & 5.64 \\
\hline Snow Hill 2 SW & 318060 & 21 & 16 & 22 & 5.41 & 4.03 & 5.57 \\
\hline Scotland Neck No. 2 & 317725 & 14 & 23 & 24 & 3.63 & 5.68 & 5.92 \\
\hline Williamston $1 \mathrm{E}$ & 319440 & 57 & 55 & 55 & 19.72 & 17.95 & 17.88 \\
\hline Wilson 3 SW & 319476 & 17 & 8 & 4 & 6.84 & 2.66 & 1.17 \\
\hline Zebulon 3 SW & 319923 & 14 & 20 & 25 & 7.88 & 11.25 & 13.29 \\
\hline Average & & 18 & 18 & 16 & 7.51 & 7.30 & 6.53 \\
\hline
\end{tabular}

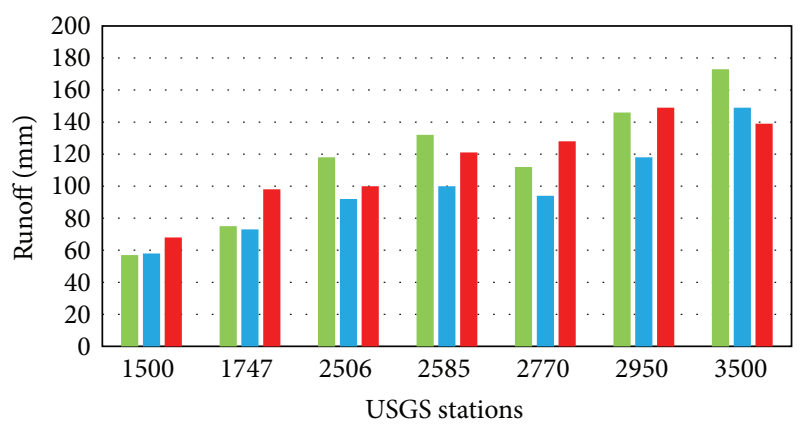

- Climate2 simulated

- WRF output simulated

- USGS measured

FIGURE 11: Comparison among the runoff (in mm/day/unit area) simulated by using observed precipitation at weather stations, the runoff simulated by using the WRF output precipitation from the CTRL experiment, and the USGS observed runoff at seven gage stations in Tar-Pamlico River Basin.

demonstrates the environmental precipitation as a percentage of the total precipitation (control run) in domains 1, 2, and 3 at the weather stations. For these stations, the precipitation due to the synoptic environment alone (without consideration of the interaction between the synoptic environment and Hurricane Floyd) is relatively less than the total precipitations. Only coastal stations of Greenville and Williamston $1 \mathrm{E}$ are over $15 \%$ of the total precipitation. Table 2 lists the precipitations from the ENV experiment at the weather stations as well as their comparisons with the results from the CTRL experiment. It is indicated that on average only $7 \%$ of the total event precipitation is created by atmospheric environment in the study area. However, over the innermost domain (domain 3), 22\% of the total precipitation is induced by the large-scale atmospheric environment. Without the vortex of Floyd, the main rainfall area was shifted eastward, with most of the synoptic environment-induced precipitation being located along the coast region (Figure 6(c)). This analysis confirms that the interaction of Floyd with the synoptic environment is a significant factor leading to the heavy observed rainfall, consistent with Colle [4] and Atallah and Bosart [3]. It should also be pointed out that despite the direct contribution from the synoptic environment to the precipitation over the watershed of interest in this study the environment can also contribute to the precipitation by interacting with the tropical system.

3.4. Comparison of Surface Runoffs. The model simulated precipitation (Figures 6(a) and 6(c)) at about 40 points from the WRF model grids (see Figure 2(a)) serves as input data into AnnGNPS model to simulate the total runoff. Figure 11 presents comparisons of three surface runoffs from (1) AnnAGNPS simulated runoff from input precipitation by WRF model output; (2) AnnAGNPS simulated runoff from input precipitation at weather stations; and (3) USGS measured runoff (unit is $\mathrm{mm}$ per day per unit area). The simulation was conducted for seven USGS stations. Station Tarboro (02083500, hereafter referred to as 3500) is the outlet of the watershed. Each station represents part of the subwatershed from the upper portion of the stream to downstream. It can be seen that the runoffs simulated by using precipitations from WRF output are comparable to those simulated by using observed precipitations at the weather stations. Both of them are in good agreement with the USGS measurements. For station 3500, the simulated surface runoff from WRF output matches the USGS measured results better. For the upper stream stations 1500 and 2506, simulated results using WRF output precipitations also agree with USGS measured values better than those using observed precipitations at the weather stations. However, for some middle stations (2770 and 2950), the simulated results tend to underestimate surface runoff. It 


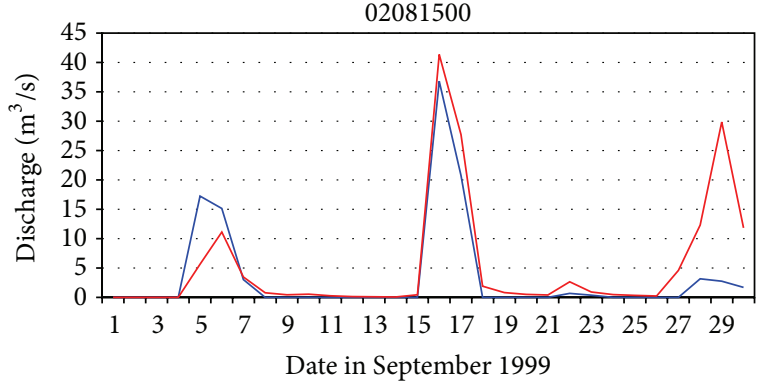

(a)

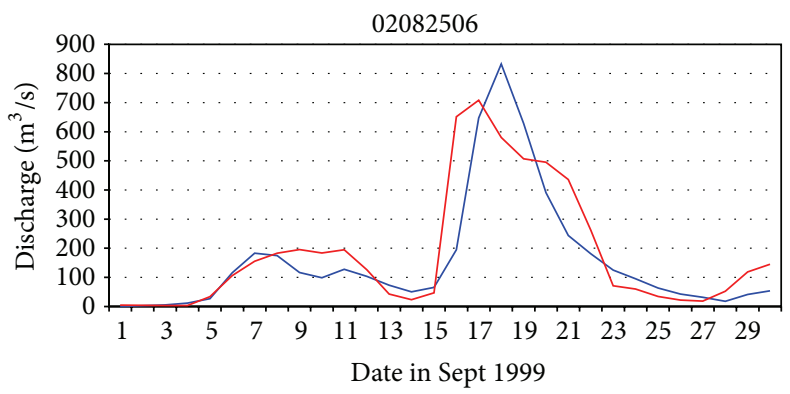

(c)

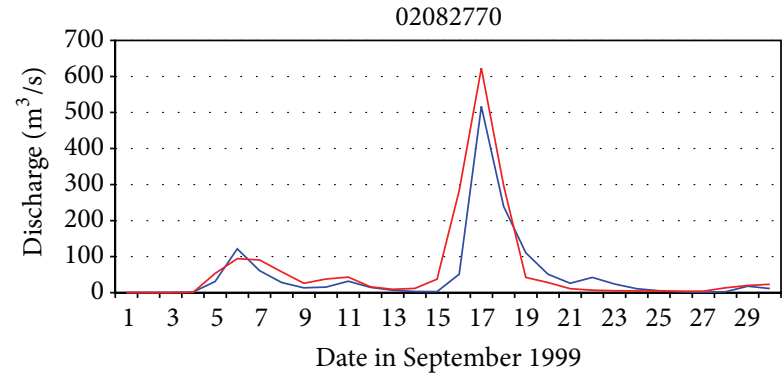

(e)

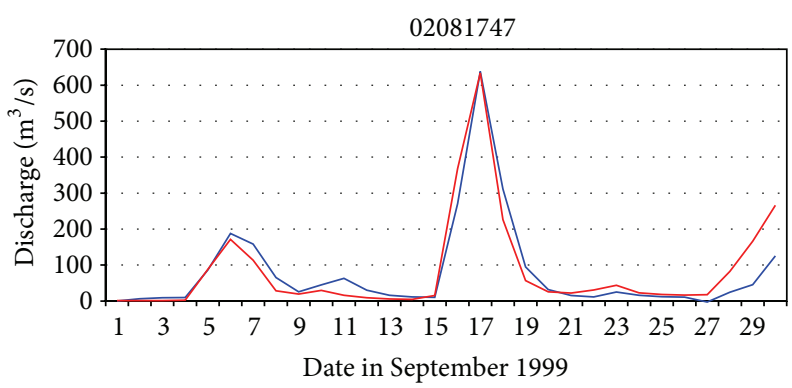

(b)

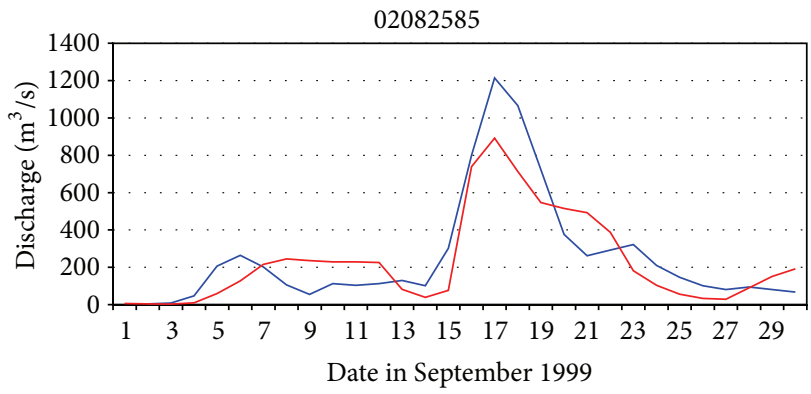

(d)

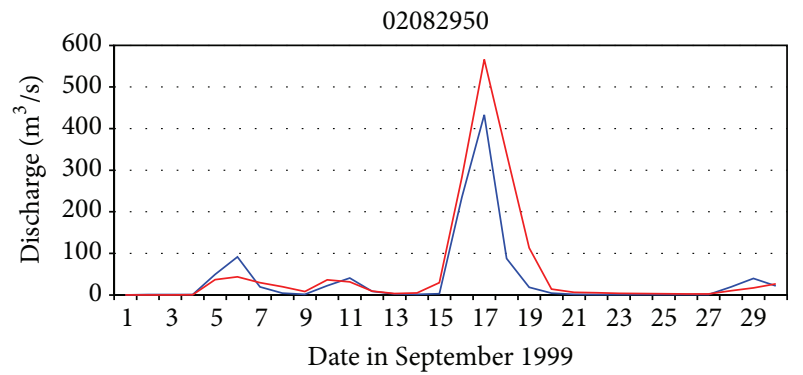

(f)

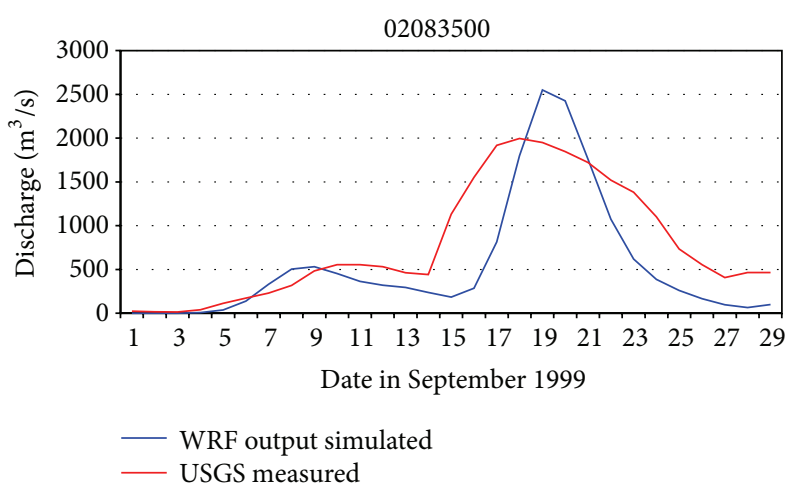

(g)

FIGURE 12: Hydrographs comparison of AnnGNPS simulated river discharge with USGS measured ones in September 1999 at gages (a) 02081500, (b) 02081747, (c) 02082506, (d) 02082585, (e) 02082770, (f) 02082950, and (g) 02083500. WRF model simulated precipitation was used to drive the hydrological model during September 16-17, whereas, for other time periods, observed precipitation from the weather stations was used to drive the hydrological model.

should be noted that USGS stream flow data at station 2950 during Floyd were estimated values and might not be very accurate. This might be due to the fact that the WRF output gridded precipitation provides better resolution to capture the detailed precipitation pattern; however, it still has model errors against observed precipitation.

Figure 12 demonstrates the simulated daily discharge hydrographs using precipitation from the CTRL simulation 
on September 16 and 17 (for the rest of days using observed precipitation) at the above-mentioned seven USGS gages after applying Muskingum stream routing [5]. The unit is $\mathrm{m}^{3} \mathrm{~s}^{-1}$. The USGS measured river discharges in September 1999 were also shown (Hurricane Dennis on September 5, and Floyd on September 16, 1999). The simulated results show good agreement with the USGS measured discharges. For upper stations (1500 and 1747), the simulated discharges are very close to those measured by the USGS, as it is easier to parameterize smaller subwatersheds at upper stream than larger subwatershed at downstream. The stream flow due to Hurricane Dennis can be clearly simulated at upper stream stations. However, downstream hydrographs demonstrate delay effects after rainfall so that discharge from Dennis cannot be reflected at station 3500 and is only slightly reflected at stations 2585 and 2950 . These are still much better results than data from Climate Station Set 2.

For the simulation by using the precipitation induced by Hurricane Floyd only (the CTRL run precipitation minus the ENV run precipitation), the total runoff is reduced by about $10 \%$ in the Tar-Pamlico River Basin (figure not shown here). This is because the precipitation induced only by the synoptic environment accounts for only $7 \%$ of the total precipitation in the watershed area. And also the impact of the interaction between the synoptic environment (e.g., the mid-latitude trough) and Hurricane Floyd has already been included in this simulation. Otherwise, the intensity and track of Hurricane Floyd would have changed without the mid-latitude trough.

\section{Conclusions}

In this study, large-scale synoptic environmental impacts on river discharge in the Tar-Pamlico River Basin during Hurricane Floyd in 1999 were investigated. The percentage of environment-induced precipitation has been quantified with the aid of the vortex removal technique. Precipitation during the landfall of Hurricane Floyd was simulated by using the WRF model with triple-nested domains and high-resolution grids in the watershed area. The WRF model reproduced the narrow axis and intense band of heavy precipitation that developed inland of the coast over North Carolina. The distribution pattern of the model simulated accumulated precipitation is consistent with the observed rainfall. Analysis in this study also confirmed that Floyd did intensify shortly after landfall during the interaction with mid-latitude trough. This point has been stated by Atallah and Bosart [3] but contested by Colle [4]. Another finding is that by using the high-resolution precipitation data from a dynamical numerical weather prediction model for input in a hydrological model improves the prediction of total runoff. This could extend lead time for flood warnings to a couple of days or beyond.

During landfall, the environmental contribution to rainfall alone was as high as $22 \%$ in innermost domain, which covers much of North Carolina, though it only contributed $7 \%$ of rainfall in the focused hydrological area. The synopticscale environment alone would contribute approximately $10 \%$ to the total Tar-Pamlico River runoff as measured at the
Tarboro gage station. Thus, the simulated impact of synoptic-scale flow alone (without consideration of interaction between the synoptic environment and the hurricane) on the total precipitation is within the margin of model error within the focused watershed area. Therefore, the results from this study indicate that the bulk of the record-breaking river runoff in the Tar-Pamlico River Basin during the landfall of Hurricane Floyd was the result of Hurricane Floyd and Hurricane Dennis and their interactions with the synoptic environment.

Although the vortex removal technique is used in this study to remove the vortex associated with Hurricane Floyd, more sensitivity analyses are needed to further test this method. Other vortex removal techniques, such as potential vorticity inversion techniques, should be explored and compared with the TC-removal procedure used in this study. On the other hand, instead of removing the vortex associated with Hurricane Floyd, an investigation by removing the synoptic trough interacting with it to isolate the impacts of the hurricane alone may be an interesting topic for future study.

\section{Acknowledgments}

This study was supported by the National Oceanic and Atmospheric Administration Grant no. NA07NWS4680002, the National Oceanic and Atmospheric Administration Climate Change Program via a subcontract (UF-EIES-1100031NCS) from the University of Florida, and IOOS Program through Award no. NA11NOS0120033\&CFDA\#11-012 via the SECOORA Program. The authors are also grateful to NCAR/NCEP for making the NARR data available, USDA for AnnAGNPS model, USGS for all hydrological data, and North Carolina State Climate Office for both surface and ground water data.

\section{References}

[1] E. Atallah, L. F. Bosart, and A. R. Aiyyer, "Precipitation distribution associated with landfalling tropical cyclones over the eastern United States," Monthly Weather Review, vol. 135, no. 6, pp. 2185-2206, 2007.

[2] M. B. Lawrence, L. A. Avila, J. L. Beven, J. L. Franklin, J. L. Guiney, and R. J. Pasch, "Atlantic hurricane season of 1999," Monthly Weather Review, vol. 129, no. 12, pp. 3057-3084, 2001.

[3] E. H. Atallah and L. F. Bosart, "The extratropical transition and precipitation distribution of hurricane Floyd (1999)," Monthly Weather Review, vol. 131, no. 6, pp. 1063-1081, 2003.

[4] B. A. Colle, "Numerical simulations of the extratropical transition of Floyd (1999): structural evolution and responsible mechanisms for the heavy rainfall over the Northeast United States," Monthly Weather Review, vol. 131, pp. 2905-2926, 2003.

[5] Q. Tang, L. Xie, and B. Liu, "Modeling tropical cyclone induced stream flow in tar pamlico river of North Carolina," Tropical Cyclone Research and Review, vol. 1, pp. 402-417, 2012.

[6] D. Hanley, J. Molinari, and D. Keyser, "A composite study of the interactions between tropical cyclones and upper-tropospheric troughs," Monthly Weather Review, vol. 129, no. 10, pp. 25702584, 2001. 
[7] S. K. Kimball and J. L. Evans, "Idealized numerical simulations of hurricane-trough interaction," Monthly Weather Review, vol. 130, no. 9, pp. 2210-2227, 2002.

[8] M. S. Peng, R. N. Maue, C. A. Reynolds, and R. H. Langland, "Hurricanes Ivan, Jeanne, Karl (2004) and mid-latitude trough interactions," Meteorology and Atmospheric Physics, vol. 97, no. 1-4, pp. 221-237, 2007.

[9] E. B. Rodgers and H. F. Pierce, "Environmental influence on Typhoon Bobbie's precipitation distribution," Journal of Applied Meteorology, vol. 34, no. 11, pp. 2513-2532, 1995.

[10] J. D. Bales, "Effects of hurricane floyd inland flooding, september-october 1999, on tributaries to pamlico sound, North Carolina," Estuaries, vol. 26, no. 5, pp. 1319-1328, 2003.

[11] M. S. Croke, Examining Planetary, Synoptic and Mesoscale Features that Enhance Precipitation Associated with Landfalling Tropical Cyclone in North Carolina, North Carolina State University, 2005.

[12] L. F. Bosart and G. M. Lackmann, "Postlandfall tropical cyclone reintensification in a weakly baroclinic environment: a case study of hurricane david (September 1979)," Monthly Weather Review, vol. 123, pp. 3268-3291, 1995.

[13] P. A. Harr and R. L. Elsberry, "Extratropical transition of tropical cyclones over the western North Pacific. Part I: evolution of structural characteristics during the transition process," Monthly Weather Review, vol. 128, no. 8, pp. 2613-2633, 2000.

[14] P. A. Harr, R. L. Elsberry, and T. F. Hogan, "Extratropical transition of tropical cyclones over the Western North Pacific Part II: the impact of midlatitude circulation characteristics," Monthly Weather Review, vol. 128, no. 8, pp. 2634-2653, 2000.

[15] L. F. Bosart, C. S. Velden, W. E. Bracken, J. Molinari, and P. G. Black, "Environmental influences on the rapid intensification of hurricane Opal (1995) over the Gulf of Mexico," Monthly Weather Review, vol. 128, no. 2, pp. 322-352, 2000.

[16] J. Molinari, S. Skubis, and D. Vollaro, "External influences on hurricane intensity. Part III: potential vorticity structure," Journal of the Atmospheric Sciences, vol. 52, no. 20, pp. 3593-3606, 1995.

[17] J. Molinari, S. Skubis, D. Vollaro, F. Alsheimer, and H. E. Willoughby, "Potential vorticity analysis of tropical cyclone intensification," Journal of the Atmospheric Sciences, vol. 55, no. 16, pp. 2632-2644, 1998.

[18] J. Molinari and D. Vollaro, "External influences on hurricane intensity. Part I: outflow layer eddy angular momentum fluxes," Journal of the Atmospheric Sciences, vol. 46, no. 8, pp. 1093-1105, 1989.

[19] J. Molinari and D. Vollaro, "External influences on hurricane intensity. Part II: vertical structure and response of the hurricane vortex," Journal of the Atmospheric Sciences, vol. 47, no. 15, pp. 1902-1918, 1990.

[20] A. S. Levine, Intensity Changes of Recurving Typhoons from a potential Vorticity Perspective, University of Hawaii, 2003.

[21] K. A. Hill and G. M. Lackmann, "Influence of environmental humidity on tropical cyclone size," Monthly Weather Review, vol. 137, no. 10, pp. 3294-3315, 2009.

[22] C. J. Matyas, "Associations between the size of hurricane rain fields at landfall and their surrounding environments," Meteorology and Atmospheric Physics, vol. 106, no. 3-4, pp. 135-148, 2010.

[23] P. M. Klein, P. A. Harr, and R. L. Elsberry, "Extratropical transition of western North Pacific tropical cyclones: an overview and conceptual model of the transformation stage," Weather and Forecasting, vol. 15, no. 4, pp. 373-395, 2000.
[24] S. L. Harville, Effects of Appalachian Topography on Precipitation From Landfalling Hurricanes, North Carolina State University, 2009.

[25] W. C. Skamarock, J. B. Klemo, J. Dudhia et al., A Description of the Advanced Research WRF Version 2, Boulder, Colo, USA, 2005.

[26] W. Wang, C. Bruyere, M. Duda et al., WRF Version 3 Modeling System User's Guide [M], 2010.

[27] R. L. Bingner, F. D. Theurer, and Y. Yuan, AnnAGNPS Technical Processes Documentation: Version 4. 0, USDA-ARS, National Sedimentation Laboratory, Oxford, Miss, USA, 2007.

[28] S. Fredrick, C. Davis, D. Gill et al., Bogussing of Tropical Cyclones in WRF Version 3.1 [M], vol. 6, National Center for Atmospheric Research, Boulder, Colo, USA, 2009.

[29] S. Y. Hong and J. O. Lim, "The WRF single-moment 6-class microphysics scheme (WSM6)," Journal of the Korean Meteorological Society, vol. 42, pp. 129-151, 2006.

[30] M. Nakanishi and H. Niino, "An improved Mellor-Yamada Level-3 model with condensation physics: its design and verification," Boundary-Layer Meteorology, vol. 112, no. 1, pp. 1-31, 2004.

[31] E. J. Mlawer, S. J. Taubman, P. D. Brown, M. J. Iacono, and S. A. Clough, "Radiative transfer for inhomogeneous atmospheres: RRTM, a validated correlated-k model for the longwave," Journal of Geophysical Research D, vol. 102, no. 14, pp. 16663-16682, 1997.

[32] J. Dudhia, "Numerical study of convection observed during the Winter Monsoon Experiment using a mesoscale twodimensional model," Journal of the Atmospheric Sciences, vol. 46, no. 20, pp. 3077-3107, 1989.

[33] J. S. Kain and J. M. Fritsch, "A one-dimensional entraining/ detraining plume model and its application in convective parameterization," Journal of the Atmospheric Sciences, vol. 47, no. 23, pp. 2784-2802, 1990.

[34] R. J. Pasch, T. B. Kiberlain, and S. R. Stewart, Preliminary Report Hurricane Floyd 7-17 September, 1999, National Hurricane Center, 1999. 

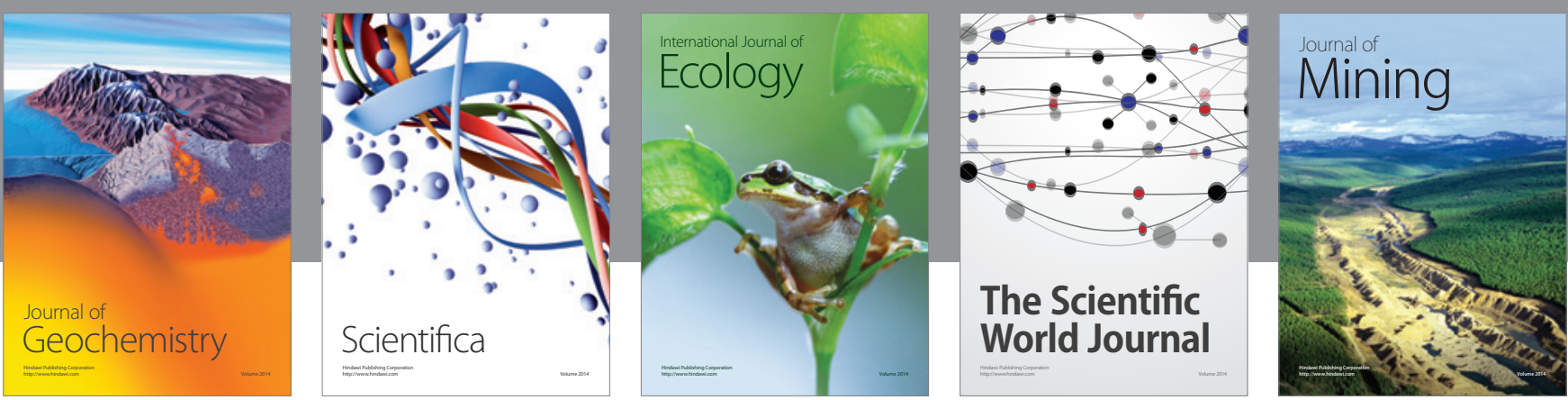

The Scientific World Journal
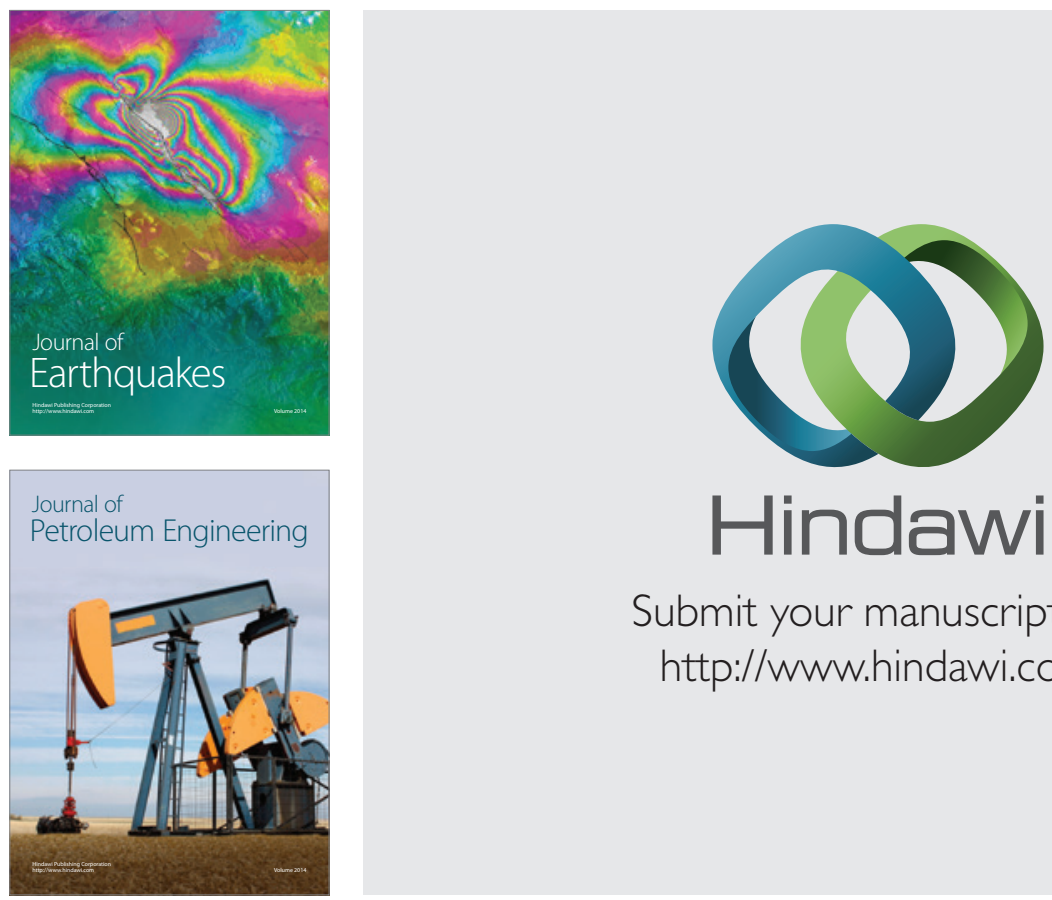

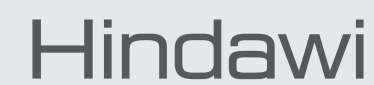

Submit your manuscripts at

http://www.hindawi.com
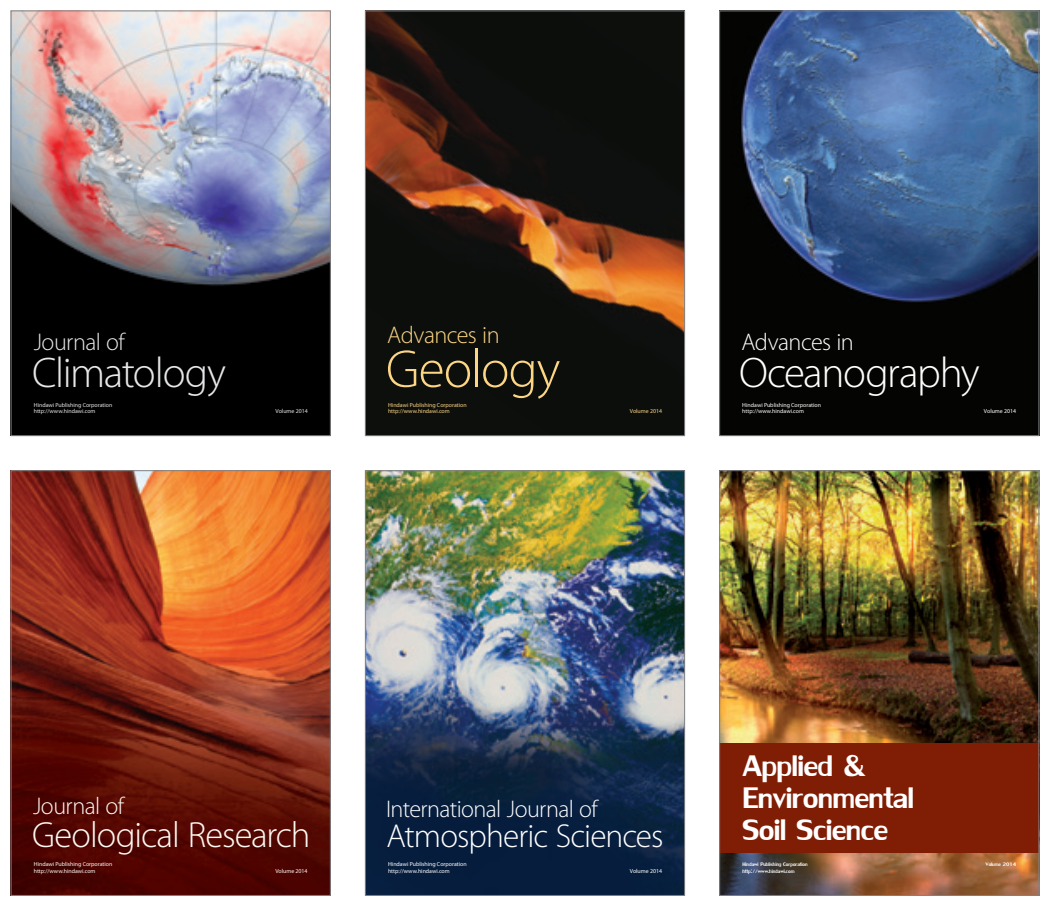
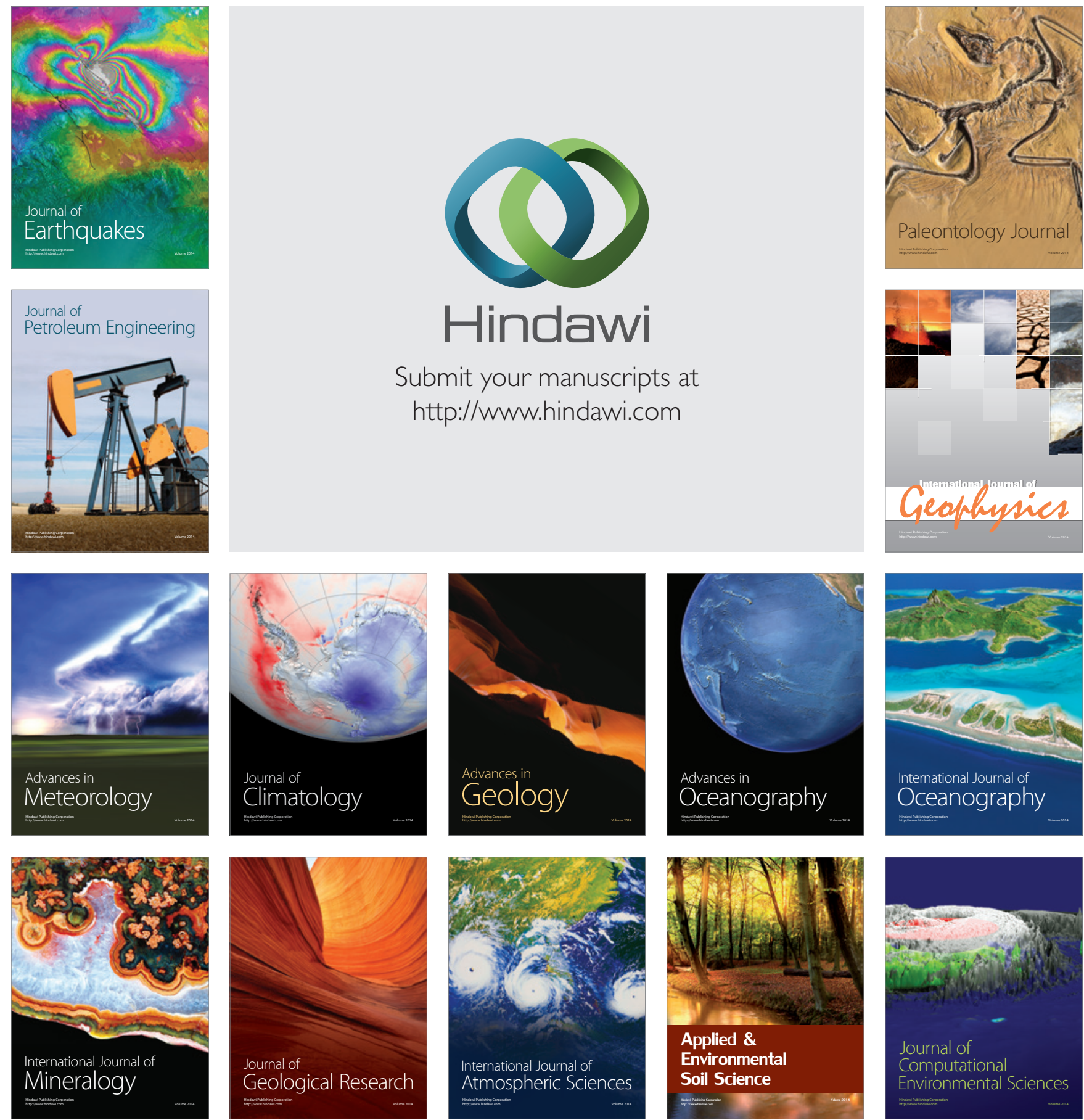